\title{
Increasing intake of long-chain n-3 PUFA enhances lipoperoxidation and modulates hepatic gene expression in a dose-dependent manner
}

\author{
Cécile Gladine ${ }^{1,2 *}$, Nicole C. Roy ${ }^{3,4,5}$, Jean-Paul Rigaudière ${ }^{1,2}$, Brigitte Laillet $^{1,2}$, Georges Da Silva ${ }^{1,2}$, \\ Charlotte Joly ${ }^{1,2,6}$, Estelle Pujos-Guillot ${ }^{1,2,6}$, Béatrice Morio ${ }^{1,2}$, Christine Feillet-Coudray ${ }^{7}$, \\ Warren C. McNabb ${ }^{3,4,5}$, Jean-Michel Chardigny ${ }^{1,2}$ and Blandine Comte ${ }^{1,2}$ \\ ${ }^{1}$ INRA, UMR 1019, UNH, CRNH Auvergne, Clermont-Ferrand, F-63122 St Genès Champanelle, France \\ ${ }^{2}$ Unité de Nutrition Humaine, Clermont Université, Université d'Auvergne, Clermont-Ferrand, France \\ ${ }^{3}$ Food Nutrition Genomics Team, Agri-Foods and Health Section, AgResearch Grasslands, Palmerston North 4442, New Zealand \\ ${ }^{4}$ Nutrigenomics, New Zealand \\ ${ }^{5}$ Riddet Institute, Massey University, Palmerston North 4442, New Zealand \\ ${ }^{6}$ INRA, UMR 1019, Plateforme d'Exploration du Métabolisme, Clermont-Ferrand, France \\ ${ }^{7}$ INRA, UMR 866, Dynamique Musculaire et Métabolisme, Montpellier, France
}

(Submitted 22 March 2011 - Final revision received 29 June 2011 - Accepted 30 June 2011 - First published online 14 September 2011)

\begin{abstract}
Long-chain (LC) $n$-3 PUFA have a broad range of biological properties that can be achieved at the gene expression level. This has been well described in liver, where LC $n$-3 PUFA modulate the expression of genes related to lipid metabolism. However, the complexity of biological pathway modulations and the nature of bioactive molecules are still under investigation. The present study aimed to investigate the doseresponse effects of LC $n-3$ PUFA on the production of peroxidised metabolites, as potential bioactive molecules, and on global gene expression in liver. Hypercholesterolaemic rabbits received by daily oral administration ( 7 weeks) either oleic acid-rich oil or a mixture of oils providing $0 \cdot 1,0.5$ or $1 \%$ (groups 1,2 and 3 respectively) of energy as DHA. Levels of specific peroxidised metabolites, namely 4-hydroxyhexenal (4-HHE)-protein adducts, issued from LC $n$-3 PUFA were measured by GC/MS/MS in liver in parallel to transcription profiling. The intake of LC $n-3$ PUFA increased, in a dose-dependent manner, the hepatic production of 4-HHE. At the highest dose, LC $n-3$ PUFA provoked an accumulation of TAG in liver, which can be directly linked to increased mRNA levels of lipoprotein hepatic receptors (LDL-receptor and VLDL-receptor). In groups 1 and 2, the mRNA levels of microsomal TAG transfer protein decreased, suggesting a possible new mechanism to reduce VLDL secretion. These modulations of genes related to lipoprotein metabolism were independent of PPAR $\alpha$ signalling but were probably linked to the activation of the farnesol X receptor pathway by LC $n-3$ PUFA and/or their metabolites such as HHE.
\end{abstract}

Key words: $\boldsymbol{n}$-3 PUFA: Lipoperoxidation: Microarray analysis: Liver: Gene expression

A plethora of data from epidemiological and experimental studies indicates that consumption of long-chain (LC) $n-3$ PUFA favourably modulates multiple biological processes involved in CVD, cancers, immune diseases, diabetes, brain health and hepatic steatosis ${ }^{(1)}$. Among the mechanisms proposed to explain the effects of LC $n$-3 PUFA, the most often reported include the metabolic interconversion into bioactive eicosanoids and/or docosanoids or the alteration of membrane self-organising lipid raft domains. More recently, LC $n-3$ PUFA have been identified as powerful gene expression modulators, notably in the liver where they are associated with the modulation of several genes related to lipid and lipoprotein metabolism, explaining their hypolipidaemic effects ${ }^{(2,3)}$.

The effects of LC $n-3$ PUFA on gene transcription were thought primarily to be mediated by a single subfamily of orphan nuclear receptors: the PPAR. However, it is now becoming evident that LC $n$-3 PUFA can affect the expression of several different genes either via direct interactions or

Abbreviations: 4-HHE, 4-hydroxyhexenal; 4-HNE, 4-hydroxynonenal; CCL4, chemokine (C-C motif) ligand 4; cRNA, complementary RNA; CXCL3, chemokine (C-X-C motif) ligand 3; ERK, extracellular signal-regulated kinase; FAME, fatty acid methyl esters; FC, fold change; FXR, farnesol X receptor; GO, Gene Ontology; IKK, IкB kinase; IPA, ingenuity pathways analysis; KLKB1, kallikrein B, plasma (Fletcher factor) 1; LC, long chain; LDLR, LDL receptor; MTTP, microsomal TAG transfer protein; SERPINA1, serpin peptidase inhibitor, clade A ( $\alpha 1$ antiproteinase, antitrypsin), member 1 ; SERPIND1, serpin peptidase inhibitor, clade D (heparin cofactor), member 1; TBARS, thiobarbituric acid-reactive substances; VLDLR, VLDL receptor.

* Corresponding author: C. Gladine, fax +334736247 55, email cecile.gladine@clermont.inra.fr 
indirectly through additional transcription factors including hepatic nuclear factor $4 \alpha$, retinoid X receptor $\alpha$, sterol regulatory element-binding protein- $1 \mathrm{c}$, liver $\mathrm{X}$ receptors $\alpha$ and $\beta$, farnesol $\mathrm{X}$ receptor (FXR) and $\mathrm{NF}-\mathrm{\kappa B}^{(4)}$. This made the uncovering of biological pathways underlying the effects of LC $n$-3 PUFA much more complex than initially thought.

Metabolism of LC $n$-3 PUFA can influence the nature of the bioactive compounds responsible for the modulation of gene expression. Indeed, LC $n$-3 PUFA are not only enzymatically metabolised into eicosanoids but they are also very prone to non-enzymatic oxidation, leading to the formation of a variety of peroxidised metabolites ${ }^{(5)}$. This reaction, known as lipid peroxidation, is particularly intense in oxidative stress conditions, making peroxidated metabolites potential key modulators of gene expression. Hydroxyalkenals are a family of aldehydes produced in abundance during peroxidation of PUFA. They comprise 4-hydroxynonenal (4-HNE) issued from n-6 PUFA and 4-hydroxyhexenal (4-HHE) generated from $n$-3 PUFA and, more specifically, DHA $(20: 6 n-3)^{(6)}$ which is the abundant $n$ - 3 PUFA in most tissues. Hydroxyalkenals, notably 4-HNE which has been identified and studied much more extensively and earlier than 4-HHE, are not only highly reactive molecules that covalently bind proteins, lipids and DNA but they are also known as signal molecules in cells ${ }^{(7)}$. This makes them interesting targets to focus on when investigating the effects of LC $n$-3 PUFA and their metabolites on the modulation of gene expression.

In this context, we hypothesised that increasing intake of LC $n-3$ PUFA could, in a dose-dependent manner, enhance the production of 4-HHE and differentially influence the expression of genes in the liver as a central organ of lipid metabolism and oxidative stress. In order to investigate these relationships, we conducted a dose-response supplementation trial in hypercholesterolaemic rabbits. The choice of this model was dictated by the need to induce a pathological condition (i.e. hypercholesterolaemia and steatosis) known to induce metabolic disturbance and inflammation ${ }^{(8)}$, which can be modulated by LC $n-3$ PUFA. Moreover, this animal model presents several advantages, among which the rapidity of the induction of hypercholesterolaemia, a lipid metabolism close to what is observed in humans, and the absence of genetic modifications making easier the understanding of gene expression modulations. The choice of an overall gene expression analysis was dictated by the need to study a complex biological system influenced by many factors including the metabolism of LC $n$-3 PUFA. This also gives the opportunity to generate new insights about the nutrigenomic effects of LC $n-3$ PUFA in the context of hypercholesterolaemia.

\section{Materials and methods \\ Animals and diets}

New Zealand White male rabbits (Charles River Laboratories, L'Arbresle, France) of 12 weeks of age (mean weight $=1874$ (SEM 138)g) were used in the present study. They were individually housed and maintained under conventional conditions with a temperature of $22^{\circ} \mathrm{C}$ and a $12 \mathrm{~h}$ light $-12 \mathrm{~h}$ dark cycle (07.00-19.00 hours). After 3 weeks of adaptation, rabbits were allocated to four experimental groups (i.e. control; LC $n$-3 PUFA-dose 1 or group 1; LC $n$-3 PUFA-dose 2 or group 2; LC $n$-3 PUFA-dose 3 or group 3 ) according to their weights and plasma cholesterol concentrations in order to obtain homogeneous groups on these two criteria. Then, animals were fed daily for 7 weeks with $100 \mathrm{~g}$ of a cholesterol-enriched diet (Table 1) providing $0.5 \mathrm{~g}$ cholesterol $/ \mathrm{d}$ per rabbit. At the same time $5 \mathrm{~d}$ /week, rabbits received $2 \mathrm{ml}$ of either oleic acid-rich sunflower oil (Lesieur, Asnières-surSeine, France; control, $n$ 6) or a mix of oleic acid-rich sunflower oil and purified tuna oil (Tuna oil 25DHA, Qualitysilver; Polaris, Pleuven, France) providing 0 $1 \%$ (LC $n$-3 PUFAdose 1 or group $1, n 8$ ), $0.5 \%$ (LC $n$-3 PUFA-dose 2 or group $2, n 8$ ) or $1 \%$ (LC $n-3$ PUFA-dose 3 or group $3, n 7$ ) of energy as DHA (22:6n-3). The first dose (dose 1) has been chosen to mimic the nutritional recommendation for DHA in the human $\operatorname{diet}^{(9)}$, whereas doses 2 and 3 are supra-nutritional, comparable with what is often used in intervention studies. Oil mixtures were prepared in advance in glass bottles sealed under $\mathrm{N}_{2}$ and stored at $4^{\circ} \mathrm{C}$ in the dark until use to prevent fatty acid peroxidation. Animals were weighed once per week and food intake was recorded five times per week. There were no statistical differences between the groups for these two parameters (data not shown). All animals were maintained and handled according to the recommendations of the Institutional Ethics Committee of the INRA, in accordance with decree no. 87-848.

\section{Sample collection}

After 7 weeks of the diet, overnight fasted rabbits were anaesthetised with pentobarbital $(30 \mathrm{mg} / \mathrm{kg}$, intravenously). Blood was collected from the marginal ear vein in tubes containing EDTA $(3 \mathrm{~mm}, \mathrm{pH} 8.2)$ and butylated hydroxytoluene $(0.44 \mathrm{mg} / \mathrm{ml}$ fresh blood). Plasma was recovered by centrifugation $\left(2700 \mathrm{~g}, 10 \mathrm{~min}, 4^{\circ} \mathrm{C}\right)$ and rapidly distributed into $1.5 \mathrm{ml}$ microtubes, flushed with $\mathrm{N}_{2}$ and frozen in liquid $\mathrm{N}_{2}$. Liver was rapidly removed, rinsed with $0.9 \%$

\begin{tabular}{lc} 
Table 1. Composition of the cholesterol-enriched diet \\
given to New Zealand White rabbits during the 7 -week \\
experiment \\
\hline Ingredients & DM $(\mathrm{g} / \mathrm{kg})$ \\
\hline Alfalfa & 305 \\
Beetroot pulp & 100 \\
Barley & 90 \\
Sunflower meal & 75 \\
Soyabean meal & 240 \\
Sucrose & 105 \\
Palm oil & 36 \\
Rapeseed oil & 24 \\
Cholesterol & 5 \\
Vitamin and mineral mix & 5 \\
D,L- $\alpha-$ Tocopherol acetate & 0.03 \\
NaCl & 5 \\
Calcium phosphate & 5 \\
\hline
\end{tabular}
given to New Zealand White rabbits during the 7 -week experiment 
$\mathrm{NaCl}$ and a sample (approximately $5 \mathrm{~g}$ ) was collected from the left lobe, frozen in liquid $\mathrm{N}_{2}$ and stored at $-80^{\circ} \mathrm{C}$ until further analysis.

\section{Fatty acid composition of liver phospholipids}

Total lipids were extracted from liver samples, as described by Folch et $a l^{(10)}$, and subsequently separated into neutral and polar lipids by solid-phase extraction (C18 SPE cartridge; Macherey-Nagel, Hoerdt, France). The solid phase extraction cartridges were washed with chloroform $(4 \mathrm{ml})$ to elute neutral lipids followed by $8 \mathrm{ml}$ methanol to elute polar lipids ${ }^{(11)}$. Phospholipids were evaporated to dryness under a gentle stream of $\mathrm{N}_{2}$ and dissolved in methanol and toluene $(4: 1, \mathrm{v} / \mathrm{v})$ for methylation. Phospholipid fatty acid methyl esters (FAME) were obtained after trans-esterification with sodium methoxide in methanol (Sigma-Aldrich, St Louis, MO, USA) followed by acid trans-esterification with boron trifluoride in methanol $\left(14 \%\right.$; Sigma-Aldrich) ${ }^{(12)}$.

GC analysis of FAME was performed using a gas chromatograph GC Trace (Thermo Fischer Scientific, Courtaboeuf, France), equipped with a fused silica CP-Sil 88 capillary column (100\% cyanopropyl-polysiloxane, $100 \mathrm{~m}, 0.25 \mathrm{~mm}$ in inner diameter, $0.20 \mu \mathrm{m}$ in film thickness; Varian S.A, Les Ulis, France), a programmed temperature vaporisation injector $\left(250^{\circ} \mathrm{C}\right)$ and a flame-ionisation detector. The sample $(1 \mu \mathrm{l})$ was injected in the splitless mode. The oven temperature programme ran between 70 and $225^{\circ} \mathrm{C}$ in four separate steps. He gas was used as a carrier, with a constant pressure $(264 \mathrm{kPa})$. The identities of sample methyl esters were determined by comparing their relative retention times with those of external well-known FAME standards (Supelco ${ }^{\mathrm{TM}} 37$ Component Fatty Acid Methyl Esters Mix and Menhaden Oil; Sigma Aldrich, St Quentin Fallavier, France). Other standard FAME mixtures were obtained from Nu-Chek-Prep (Elysian, MN, USA).

\section{Plasma lipid profiles}

Plasma samples were analysed for their contents in total cholesterol, HDL-cholesterol, TAG and apoB using a Konelab 20 analyser (Thermo Electron SA, Cergy-Pontoise, France). LDL-cholesterol concentration was calculated by the Friedewald equation as follows:

$$
\begin{aligned}
\text { LDL-cholesterol }(\mathrm{mg} / \mathrm{l})= & \text { total cholesterol }- \text { HDL-cholesterol } \\
& -(\mathrm{TAG} / 5) .
\end{aligned}
$$

\section{TAG and cholesterol concentration in liver}

Liver samples (200 mg) were homogenised in a saline solution $(500 \mu \mathrm{l})$ with a Polytron homogeniser PT-MR2100 (Kinermatica AG, Littau/Luzern, Switzerland) and lipids were extracted by chloroform-methanol $(2: 1, \mathrm{v} / \mathrm{v})$ with overnight agitation. The chloroform phase was recovered after centrifugation and evaporated under dry air. Lipids (including TAG) were then saponified with $0.5 \mathrm{~mm}-\mathrm{KOH}-$ ethanol at $70^{\circ} \mathrm{C}$ for $30 \mathrm{~min}$ followed by the addition of $0 \cdot 15 \mathrm{~mm}^{-\mathrm{MgSO}_{4}}$ to neutralise the mixture. After centrifugation (2000 g, $5 \mathrm{~min}$ ), glycerol from TAG in the supernatant was estimated by an enzymatic assay (TG PAP 150 kits; Bio-Merieux, Marcyl'Etoile, France). Cholesterol in the lipid residue was dissolved in isopropanol and measured enzymatically (Cholesterol RTUTM; Bio-Merieux).

\section{Glutathione system}

Liver contents of reduced glutathione and glutathione disulphide (oxidised glutathione) were measured according to the method of Griffith ${ }^{(13)}$. The enzymatic activities of glutathione peroxidase, glutathione reductase and glutathione- $S$ transferase were assessed as already described by Flohe \& Gunzler $^{(14)}$, Carlberg \& Mannervik ${ }^{(15)}$ and Habig et $a l .{ }^{(16)}$, respectively.

\section{Lipoperoxidation biomarkers}

Concentrations of thiobarbituric acid-reactive substances (TBARS), as indices of global lipid peroxidation, were measured in liver homogenates according to the method of Sunderman et $a l .{ }^{(17)}$. Moreover, to determine the specific peroxidation of $n-6$ and $n$ - 3 PUFA, we measured the hepatic concentrations of thioether protein adducts with HNE (4-HNE-P) and HHE (4-HHE-P), respectively. Because of the high reactivity of hydroxyalkenals, the measurement of protein adducts is a more reliable lipoperoxidation biomarker. These adducts were assessed by GC/MS. Sample preparation was done according to the method described by Asselin et al. ${ }^{(18)}$. Briefly, $100 \mathrm{mg}$ of liver tissue were mixed with $1 \mathrm{ml}$ of cold buffer $(\mathrm{pH}$ 7.0) containing $39 \mathrm{~mm}$-HEPES, $0.4 \mathrm{~mm}$-EDTA and 0.9 mm-butylated hydroxytoluene and immediately treated with $1.14 \mathrm{~mm}-$ $\mathrm{NaB}^{2} \mathrm{H}_{4}$ to reduce aldehydes into their chemically stable ${ }^{2} \mathrm{H}-$ labelled alcohol derivatives. Then, proteins were precipitated with saturated sulfosalicylic acid $(0 \cdot 2 \mathrm{ml})$. After centrifugation, the protein pellet was resuspended into $8 \mathrm{~mm}$-guanidine buffer (0.5 ml), $0.25 \mathrm{nmol}$ of the labelled internal standard $\left[{ }^{2} \mathrm{H}_{11}\right]$ (TBDMS) were added, and an incubation with Raney nickel (approximately $2 \mathrm{~g}$ ) was performed (overnight, $55^{\circ} \mathrm{C}$ ) in order to cleave the thioether linkages and reduce the $\mathrm{C}-$ $\mathrm{C}$ bonds. Free saturated derivatives were then extracted three times with ethyl acetate. The extract was evaporated under a gentle stream of $\mathrm{N}_{2}$ and treated with $75 \mu \mathrm{N}$-methyl$\mathrm{N}$-( $t$-butyldimethylsylyl)-trifluoroacetamide 1,4-dihydroxynonene (DHN) for $2 \mathrm{~h}$ at $80^{\circ} \mathrm{C}$ for derivatisation. Samples were analysed using a triple quadrupole mass spectrometer Quattro Micro (Waters Corporation, Manchester, UK) coupled with a GC Agilent 6890N system (Agilent Technologies, Palo Alto, CA, USA), operating in the positive chemical ionisation mode using isobutane as the reagent gas. Injections $(1 \mu \mathrm{l})$ were made at $250^{\circ} \mathrm{C}$ in the split mode $(1 / 20)$. The carrier gas was high-purity He at a constant flow rate of $0.7 \mathrm{ml} / \mathrm{min}$. Chromatographic separation was performed using an HP-5MS Agilent Technologies capillary column $(50 \mathrm{~m} \times 0.2 \mathrm{~mm}$ in inner diameter $\times 0.33 \mu \mathrm{m}$ in phase thickness; Agilent Technologies) under the following conditions: $170^{\circ} \mathrm{C}$ for $1 \mathrm{~min}$, increased by 
$10^{\circ} \mathrm{C} / \mathrm{min}$ until $220^{\circ} \mathrm{C}, 2^{\circ} \mathrm{C} / \mathrm{min}$ until $235^{\circ} \mathrm{C}, 5^{\circ} \mathrm{C} / \mathrm{min}$ until $250^{\circ} \mathrm{C}$ and then by $30^{\circ} \mathrm{C} / \mathrm{min}$ until $300^{\circ} \mathrm{C}$. At the end of each run, temperature was kept at $300^{\circ} \mathrm{C}$ for $5 \mathrm{~min}$ to purify the column. MS parameters were optimised using the standard solutions. Maximum sensitivity was obtained for an ion-source temperature set at $120^{\circ} \mathrm{C}$, an electron energy at $90 \mathrm{eV}$ and an emission current at $300 \mu \mathrm{A}$

Quantification was achieved by measuring product ions (multiple reaction monitoring) from the fragmentation of the protonated $[\mathrm{M}+\mathrm{H}]^{+}$molecules. Collision energy potentials were then adjusted to optimise the signal for the most abundant product (daughter) ions: $m / z 390>258$ for $\left[{ }^{2} \mathrm{H}\right] \mathrm{DHN}$ (reduced 4-HNE), $m / z 348>216$ for $\left[{ }^{2} \mathrm{H}\right]$ 1,4-dihydroxyhexene (reduced 4-HHE) and $m / z 400>268$ for the internal standard $\left[{ }^{2} \mathrm{H}_{11}\right] \mathrm{DHN}$ using argon as collision gas. Quantification was performed using calibration curves with external standards. Quantities of 4-HNE- and 4-HHE-P adducts that are reported in the present study represent averages of duplicate sample injections.

\section{RNA isolation}

Total RNA from liver tissue was isolated using the Norgen RNA Purification kit (Norgen Bioteck Corporation, Thorold, ON, Canada), according to the manufacturer's instruction. RNA was quantified with a Nanodrop ND-1000 spectrophotometer (NanoDrop Technologies, Wilmington, DE, USA), and RNA integrity assessed with a RNA 6000 Nano Labchip kit using the Agilent 2100 Bioanalyzer (Agilent Technologies, Santa Clara, CA, USA). Only total RNA with an optical density $260 / 280$ ratio $>1 \cdot 8$, an optical density $260 / 230$ ratio $>1.7$ and a RNA integrity number $>8$ was used for microarray hybridisation.

\section{Microarrays}

RNA samples were labelled using the Agilent Quick-Amp Labelling kit (5190-0424; Agilent Technologies, Wilmington, DE, USA), according to the manufacturer's instructions. Briefly, $500 \mathrm{ng}$ of purified total RNA from each sample were amplified and reverse-transcribed in vitro to complementary DNA using the T7-polymerase, which was subsequently labelled with either cyanine 3-CTP or cyanine 5-CTP dyes (5188-1170-P; Agilent Technologies). Nanodrop ND-1000 was used to monitor the yield of amplification and dye incorporation; all samples had a yield $>825 \mathrm{ng}$ complementary RNA (cRNA) and a specific activity $>8.0 \mathrm{pmol} \mathrm{Cy} 3$ or Cy 5 per $\mu \mathrm{g}$ cRNA. The fluorescently labelled cRNA was hybridised using the Agilent gene expression hybridisation kit (51885242-A; Agilent Technologies) following the manufacturer's instructions. Briefly, $825 \mathrm{ng}$ cyanine 3-labelled, linearly amplified cRNA were mixed with 825 ng cyanine 5-labelled, linearly amplified cRNA. The mix was loaded onto the Agilent Rabbit Gene Expression Microarrays ( $4 \times 44 \mathrm{k}$; Agilent Technologies) following a loop design and hybridisation proceeded in a hybridisation oven set to $65^{\circ} \mathrm{C}$ for $17 \mathrm{~h}$. Then, the slides were washed in solutions I, II and III (Agilent Technologies) and air-dried.
Slides were scanned immediately after washing using the Agilent DNA Microarray Scanner (G2565AA/G2565BA; Agilent Technologies), at photomultiplier tube voltages red and green. Spot identification and quantification were performed using Agilent Feature Extraction Software 7.0 (Agilent Technologies). The complete formatted dataset is deposited as Gene Expression Omnibus accession GSE27621, which can be accessed at http://www.ncbi.nlm.nih.gov/geo/.

\section{Analysis of microarray data}

Statistical analyses were performed using linear models for microarray analysis (Limma) from the Bioconductor project $^{(19)}$. Quality of the microarray data was assessed on diagnostic plots (box plots and density plots) and spatial images generated from the raw (non-processed) data. All twelve arrays passed these strict criteria and were included in the analyses. Intensity ratio values for all microarray spots were normalised using a global loess smoothing procedure to remove the effect of systematic variation in the microarrays and no background correction was necessary due to homogeneous hybridisation ${ }^{(20)}$. The following three experimental comparisons were performed: (1) control $v$. group 1, (2) control $v$. group 2 and (3) control $v$. group 3. For each experimental comparison, a candidate list of differentially expressed probe sets was generated by calculating a moderated $t$ statistic for each probe set using the Limma package. The Limma library implements an empirical Bayes approach to assign differential gene expression. Probe sets that satisfied the criterion of $\geq 1 \cdot 2$-fold change (FC) with a moderated $P<0.05$ were considered to be significantly different. This FC was chosen because previous studies have shown that the use of a level $\geq 1.6$ can underestimate the number of genes that are differentially regulated by a dietary treatment ${ }^{(21,22)}$

Ingenuity Pathways Analysis (IPA; Ingenuity Systems, Inc., Redwood City, CA, USA; www.ingenuity.com) was used to relate changes in gene expression levels to functional changes. The full dataset from the microarray analysis (including Entrez gene identification and gene expression values) was uploaded into IPA. The IPA library of canonical pathways identified those pathways that were most significant to the dataset. Genes differentially expressed and associated with the top 10 canonical pathways in the Ingenuity Pathways Knowledge Base are presented in the present paper. The significance of the association between a dataset and a specific canonical pathway was estimated in two ways: (1) the proportion of genes in the dataset included in the canonical pathway and (2) Fisher's exact test is used to calculate a $P$ value determining the probability of the association between the dataset and the canonical pathway.

A complementary analysis was performed using EASE (software version 2.0; National Institutes of Health, Bethesda, MD, USA) to identify enriched biological themes within gene lists using Gene Ontology (GO) category over-representation analysis $^{(23)}$. The same dataset as the one uploaded in IPA was used. An EASE score (adjusted Fisher's exact test for statistical significance) was calculated for the likelihood of overrepresentation of hierarchical categories based on biological 
processes, molecular functions and cellular components using the GO public database. Gene categories with an EASE score $<0.05$ were considered to be significantly overrepresented.

\section{Statistics}

Statistical analyses of fatty acid composition, lipoperoxidation parameters and liver glutathione level parameters were performed using GraphPad InStat version 3.06 (GraphPad Software, San Diego, CA, USA; www.graphpad.com). Data are presented as means with their standard errors ( $n$ 6-8) and followed a Gaussian distribution (Kolmogorov-Smirnov test), and differences between standard deviations (Bartlett's test) were not significant except for TBARS, TC:HDL-cholesterol, SFA and $n$-3 PUFA, which were then analysed using a non-parametric test (Kruskal-Wallis test). All other data were analysed using a one-way ANOVA, and all significant differences among means at the level of $P<0.05$ were tested with Tukey-Kramer's post hoc analysis. Differences were considered as a trend when $0.05<P<0 \cdot 1$.

\section{Results}

Effects of long-chain n-3 PUFA on fatty acid composition of liver phospholipids

Fatty acid composition of liver phospholipids was measured to assess the incorporation of dietary LC $n-3$ PUFA. Table 2 shows that the proportion of LC $n-3$ PUFA (i.e. EPA (20:5n-3), docosapentaenoic acid (DPA) (22:5n-3) and DHA $(22: 6 n-3))$ in the liver of rabbits, given the tuna oil supplements, was substantially increased in a dose-dependent manner in comparison with the control group $(4 \times, 13 \times$ and $22 \times, P<0.01$ in groups 1,2 and 3 , respectively). All the dietary treatments raised the DHA contents, reaching $15 \%$ of total fatty acids in group 3 and 100 times higher than the levels in the control group $(P<0.01)$. The incorporation of LC $n$-3 PUFA was positively correlated with the peroxidisability index $\left(r^{2} 0 \cdot 81, P<0 \cdot 001\right)$, which was twice higher in group 3 than in the control group $(P<0 \cdot 0001)$. Whatever the dose of LC $n-3$ PUFA, arachidonic acid (20:4n-6) concentration was unchanged but linoleic acid (18:2n-6) proportion decreased by 3, 20 and $44 \%$ in groups 1, 2 and 3, respectively

Table 2. Fatty acid composition (relative percentage of fatty acid methyl ester) of liver phospholipids from rabbits fed daily for 7 weeks either oleic sunflower oil (control) or a mixture of oils providing $0.1 \%$ (group 1 ), $0.5 \%$ (group 2) or $1 \%$ (group 3 ) of daily energy intake as DHA (Mean values with their standard errors, six to eight animals per group)

\begin{tabular}{|c|c|c|c|c|c|c|c|c|c|}
\hline \multirow{3}{*}{$\begin{array}{l}\text { Fatty acid } \\
\text { (\% FAME) }\end{array}$} & & & \multicolumn{6}{|c|}{ LC $n-3$ PUFA } & \multirow{3}{*}{$\begin{array}{c}\text { LC } n-3 \\
\text { PUFA effect* }\end{array}$} \\
\hline & \multicolumn{2}{|c|}{ Control } & \multicolumn{2}{|c|}{ Group 1} & \multicolumn{2}{|c|}{ Group 2} & \multicolumn{2}{|c|}{ Group 3} & \\
\hline & Mean & SEM & Mean & SEM & Mean & SEM & Mean & SEM & \\
\hline $14: 0$ & $0 \cdot 12^{a}$ & 0.01 & $0 \cdot 10^{a, b}$ & 0.01 & $0.08^{b}$ & 0.01 & $0.12^{\mathrm{a}}$ & 0.01 & $<0.01$ \\
\hline $14: 1$ & $0 \cdot 24^{a}$ & 0.01 & $0.24^{a}$ & 0.01 & $0.32^{b}$ & 0.02 & $0.30^{a, b}$ & 0.03 & $<0.01$ \\
\hline $15: 0$ & 0.35 & 0.02 & 0.31 & 0.01 & 0.32 & 0.02 & 0.41 & 0.06 & 0.12 \\
\hline $16: 0$ & $19 \cdot 82^{\mathrm{a}}$ & 0.23 & $21 \cdot 01^{a}$ & 0.48 & $25 \cdot 36^{b}$ & 0.40 & $26 \cdot 13^{b}$ & 0.81 & $<0.01$ \\
\hline $16: 1 n-9$ & $0.12^{a, b}$ & 0.02 & $0 \cdot 13^{b}$ & 0.01 & $0 \cdot 10^{a, b}$ & 0.01 & $0.08^{a}$ & 0.01 & 0.02 \\
\hline $16: 1 n-7$ & $0.68^{a}$ & 0.07 & $0.55^{a, b}$ & 0.04 & $0.43^{b}$ & 0.05 & $0 \cdot 36^{\mathrm{b}}$ & 0.02 & $<0.01$ \\
\hline $17: 0$ & $0.68^{a}$ & 0.03 & $0.76^{a, b}$ & 0.04 & $0.89^{b}$ & 0.02 & $0.86^{b}$ & 0.05 & $<0.01$ \\
\hline $18: 0$ & $17 \cdot 85$ & 0.42 & $18 \cdot 16$ & 0.31 & $16 \cdot 31$ & 0.42 & $17 \cdot 83$ & 0.90 & 0.08 \\
\hline $18: 1 n-9$ & $16 \cdot 26^{a}$ & 0.57 & $13 \cdot 95^{\mathrm{b}}$ & 0.61 & $9 \cdot 95^{c}$ & 0.46 & $8.44^{c}$ & 0.59 & $<0.01$ \\
\hline $18: 1 n-7$ & $1.92^{a}$ & 0.08 & $1 \cdot 71^{a}$ & 0.05 & $1 \cdot 38^{b}$ & 0.04 & $1 \cdot 32^{b}$ & 0.02 & $<0.01$ \\
\hline $18: 2 n-6$ & $30 \cdot 41^{a}$ & 0.56 & $29 \cdot 47^{a}$ & 0.69 & $24 \cdot 24^{b}$ & 0.47 & $17 \cdot 07^{c}$ & 0.81 & $<0.01$ \\
\hline $20: 1 n-11$ & $0 \cdot 31^{a}$ & 0.02 & $0.26^{a}$ & 0.02 & $0.18^{b}$ & 0.02 & $0.14^{b}$ & 0.01 & $<0.01$ \\
\hline $18: 3 n-3$ & $1 \cdot 24^{\mathrm{a}}$ & 0.12 & $0.99^{a}$ & 0.05 & $0.67^{b}$ & 0.08 & $0.53^{b}$ & 0.08 & $<0.01$ \\
\hline $20: 2 n-6$ & $0.44^{a}$ & 0.03 & $0.41^{a}$ & 0.04 & $0.26^{b}$ & 0.02 & $0.18^{b}$ & 0.01 & $<0.01$ \\
\hline $20: 3 n-9$ & $0 \cdot 16^{a}$ & 0.01 & $0 \cdot 16^{a}$ & 0.01 & $0 \cdot 11^{b}$ & 0.01 & $0.06^{c}$ & 0.01 & $<0.01$ \\
\hline $20: 3 n-6$ & $0.78^{a}$ & 0.02 & $0.79^{a}$ & 0.02 & $0.62^{b}$ & 0.03 & $0.44^{c}$ & 0.03 & $<0.01$ \\
\hline $20: 4 n-6$ & $6 \cdot 86$ & 0.31 & 6.91 & 0.31 & $7 \cdot 23$ & 0.22 & 7.04 & 0.17 & 0.75 \\
\hline $20: 5 n-3$ & $0 \cdot 11^{a}$ & 0.01 & $0 \cdot 20^{\mathrm{a}}$ & 0.01 & $0.72^{b}$ & 0.06 & $1 \cdot 33^{\mathrm{c}}$ & 0.06 & $<0.01$ \\
\hline $22: 4 n-6$ & $0.58^{a}$ & 0.03 & $0.39^{b}$ & 0.03 & $0.21^{c}$ & 0.02 & $0.13^{c}$ & 0.01 & $<0.01$ \\
\hline $22: 5 n-6$ & $0 \cdot 24^{a}$ & 0.02 & $0.25^{\mathrm{a}}$ & 0.02 & $0.36^{b}$ & 0.02 & $0.37^{b}$ & 0.03 & $<0.01$ \\
\hline $22: 5 n-3$ & $0.55^{a}$ & 0.03 & $0.63^{a, b}$ & 0.05 & $0.93^{b}$ & 0.04 & $1 \cdot 50^{C}$ & 0.16 & $<0.01$ \\
\hline $22: 6 n-3$ & $0 \cdot 15^{a}$ & 0.01 & $2 \cdot 47^{\mathrm{b}}$ & 0.11 & $9 \cdot 10^{c}$ & 0.40 & $15 \cdot 15^{d}$ & 0.68 & $<0.01$ \\
\hline$\Sigma$ SFA & $38 \cdot 83^{a}$ & 0.38 & $40 \cdot 36^{a}$ & 0.23 & $43 \cdot 00^{b}$ & 0.26 & $45 \cdot 38^{c}$ & 0.63 & $<0.01$ \\
\hline$\Sigma$ MUFA & $19 \cdot 53^{a}$ & 0.69 & $16 \cdot 85^{\mathrm{b}}$ & 0.67 & $12 \cdot 38^{c}$ & 0.56 & $10 \cdot 64^{c}$ & 0.62 & $<0.01$ \\
\hline$\Sigma$ PUFA & $41 \cdot 51^{a}$ & 0.47 & $42 \cdot 67^{\mathrm{a}, \mathrm{c}}$ & 0.51 & $44.45^{\mathrm{b}, \mathrm{c}}$ & 0.43 & $43.77^{c}$ & 0.43 & $<0.01$ \\
\hline$\Sigma n-6$ PUFA & $39 \cdot 31^{a}$ & 0.50 & $38 \cdot 22^{a}$ & 0.55 & $32 \cdot 92^{b}$ & 0.42 & $25 \cdot 22^{c}$ & 0.88 & $<0.01$ \\
\hline$\Sigma n-3$ PUFA & $2 \cdot 04^{a}$ & 0.09 & $4 \cdot 30^{\mathrm{b}}$ & 0.11 & $11 \cdot 42^{\mathrm{C}}$ & 0.38 & $18 \cdot 49^{d}$ & 0.74 & $<0.01$ \\
\hline$\Sigma$ LC $n-3$ PUFA & 0.80 & 0.04 & $3 \cdot 30^{\mathrm{b}}$ & 0.14 & $10 \cdot 75^{c}$ & 0.41 & $17 \cdot 97^{d}$ & 0.72 & $<0.01$ \\
\hline PI† & $61 \cdot 81^{a}$ & 0.84 & $72 \cdot 35^{\mathrm{b}}$ & 0.99 & $103 \cdot 16^{c}$ & $2 \cdot 19$ & $129 \cdot 28^{d}$ & 2.65 & $<0.01$ \\
\hline
\end{tabular}

LC, long-chain; FAME, fatty acid methyl esters; PI, peroxidisability index.

a,b,c,d Mean values with unlike superscript letters were significantly different $(P<0.05)$.

* Data were analysed using a one-way ANOVA, and all significant differences among means at the level of $P<0.05$ were tested with the Tukey-Kramer post hoc analysis.

$\dagger \mathrm{PI}=(\%$ dienoic $\times 1)+(\%$ trienoic $\times 2)+(\%$ tetraenoic $\times 3)+(\%$ pentaenoic $\times 4)+(\%$ hexaenoic $\times 5)$. 
Table 3. Concentration of total cholesterol, HDL-cholesterol, LDL-cholesterol, apoB100 and TAG from rabbits fed either oleic sunflower oil (control) or a mixture of oils providing $0.1 \%$ (group 1 ), $0.5 \%$ (group 2) or $1 \%$ (group 3 ) of daily energy intake as DHA (Mean values with their standard errors, six to eight animals per group)

\begin{tabular}{|c|c|c|c|c|c|c|c|c|c|}
\hline & & & \multicolumn{6}{|c|}{ Long-chain $n$-3 PUFA } & \multirow{3}{*}{$\begin{array}{l}\text { Long-chain } n-3 \\
\text { PUFA effect* }\end{array}$} \\
\hline & \multicolumn{2}{|c|}{ Control } & \multicolumn{2}{|c|}{ Group 1} & \multicolumn{2}{|c|}{ Group 2} & \multicolumn{2}{|c|}{ Group 3} & \\
\hline & Mean & SEM & Mean & SEM & Mean & SEM & Mean & SEM & \\
\hline \multicolumn{10}{|l|}{ Plasma } \\
\hline Total cholesterol (mM) & $65 \cdot 70$ & $7 \cdot 60$ & 57.54 & $3 \cdot 81$ & 66.02 & 7.52 & 59.95 & $5 \cdot 68$ & 0.75 \\
\hline HDL-cholesterol (mM) & 6.54 & 0.66 & 5.41 & 0.78 & 6.43 & 0.68 & $7 \cdot 24$ & 0.55 & 0.33 \\
\hline LDL-cholesterol (mм) & $18 \cdot 21$ & 1.87 & $17 \cdot 28$ & 0.85 & 17.67 & $2 \cdot 07$ & $15 \cdot 86$ & $2 \cdot 72$ & 0.87 \\
\hline Total:HDL-cholesterol & $10 \cdot 03$ & 0.38 & $11 \cdot 38$ & $1 \cdot 22$ & $10 \cdot 81$ & 1.32 & $8 \cdot 27$ & 0.44 & 0.17 \\
\hline LDL:HDL-cholesterol & 3.05 & 0.58 & 3.59 & 0.65 & 2.97 & 0.46 & $2 \cdot 18$ & 0.29 & 0.28 \\
\hline ApoB100 (g/l) & 0.99 & 0.17 & 0.73 & 0.10 & 0.94 & 0.15 & 1.37 & 0.18 & 0.06 \\
\hline TAG (mM) & $2 \cdot 32$ & 0.38 & $2 \cdot 66$ & 0.22 & $2 \cdot 80$ & 0.79 & 3.63 & 0.45 & 0.43 \\
\hline \multicolumn{10}{|l|}{ Liver } \\
\hline Total cholesterol $(\mu \mathrm{g} / \mathrm{mg})$ & $19 \cdot 88$ & 1.43 & $18 \cdot 91$ & 1.93 & $17 \cdot 74$ & 1.56 & $21 \cdot 86$ & 1.65 & 0.42 \\
\hline TAG $(\mu \mathrm{g} / \mathrm{mg})$ & $10 \cdot 59^{\mathrm{a}}$ & 1.26 & $12 \cdot 08^{\mathrm{a}}$ & 1.47 & $11 \cdot 74^{\mathrm{a}}$ & $1.77^{\mathrm{a}}$ & $32.92^{\mathrm{b}}$ & 8.66 & $<0.01$ \\
\hline
\end{tabular}

* Data were analysed using a one-way ANOVA, and all significant differences among means at the level of $P<0.05$ were tested with the Tukey-Kramer post hoc analysis.

$(P<0 \cdot 01)$, when compared with the control condition. More generally, the progressive incorporation of LC $n-3$ PUFA in liver phospholipids ( $17 \%$ of total FAME in group $3 v$. control) induced a similar reduction of the incorporation of $n-6$ PUFA ( $-14 \%$ of total FAME in group $3 v$. control). The concentrations of most other fatty acids were significantly changed by the LC $n$-3 PUFA supplementations but to a lesser extent.

\section{Effects of long-chain n-3 PUFA on plasma and liver lipids} and apoB100

Plasma and liver lipid profiles were determined to investigate the effects of LC $n-3$ PUFA on cholesterol and TAG metabolism. Table 3 shows that the concentrations of plasma biomarkers were unchanged by none of the LC $n-3$ PUFA doses. In liver, total cholesterol was not modified by LC $n-3$ PUFA supplementation but there was a strong increase in TAG with dose $3(3 \times$ in comparison with the control, $P<0 \cdot 01)$. This effect on TAG accumulation in liver was not dose-dependent but occurred only with the highest dose of LC $n-3$ PUFA.

\section{Effect of long-chain n-3 PUFA on liver glutathione metabolism}

Glutathione, one the main endogenous and intracellular antioxidant, and biomarkers of its metabolism were quantified in the liver in order to estimate the antioxidant status of rabbits and the effects of LC $n-3$ PUFA. None of the different parameters analysed was significantly affected by LC $n-3$ PUFA, as shown in Table 4. However, the data show that group 3 tended to have a distinct profile in comparison with the other groups. In contrast to groups 1 and 2, when comparing group 3 with the control, reduced glutathione concentration was $12 \%$ lower while oxidised glutathione $27 \%$ higher, leading to a $36 \%$ higher reduced glutathione:oxidised glutathione ratio (NS).

\section{Effect of long-chain n-3 PUFA on liver lipid peroxidation}

Several biomarkers of lipid peroxidation were measured to assess the dose-response effects of LC $n$ - 3 PUFA supplementations on the endogenous production of peroxidised metabolites (Fig. 1). As expected with regard to the

Table 4. Liver concentration of reduced (GSH) and oxidised (GSSG) glutathione (nmol/g fresh tissue) and activities (U/g protein) of glutathione peroxidase (GPX), glutathione reductase (GR) and glutathione-S-transferase (GST) from rabbits fed daily either oleic sunflower oil (control) or a mixture of oleic sunflower oil and a DHA-enriched tuna oil providing $0.1 \%$ (group 1 ), $0.5 \%$ (group 2 ) or $1 \%$ (group 3 ) of daily energy intake as DHA

(Mean values with their standard errors, six to eight animals per group)

\begin{tabular}{|c|c|c|c|c|c|c|c|c|c|}
\hline & & & \multicolumn{6}{|c|}{ Long-chain $n$-3 PUFA } & \multirow{3}{*}{$\begin{array}{l}\text { Long-chain } n-3 \\
\text { PUFA effect* }\end{array}$} \\
\hline & \multicolumn{2}{|c|}{ Control } & \multicolumn{2}{|c|}{ Group 1} & \multicolumn{2}{|c|}{ Group 2} & \multicolumn{2}{|c|}{ Group 3} & \\
\hline & Mean & SEM & Mean & SEM & Mean & SEM & Mean & SEM & \\
\hline GSH (nmol/g) & 6455 & 343 & 7013 & 252 & 6917 & 404 & 5676 & 402 & 0.13 \\
\hline GSSG (nmol/g) & 44.4 & 6.5 & $42 \cdot 6$ & 4.9 & $39 \cdot 7$ & $3 \cdot 1$ & $56 \cdot 6$ & $6 \cdot 2$ & 0.25 \\
\hline Redox potential $(\mathrm{mV}) \dagger$ & $-202 \cdot 68$ & 2.89 & $-205 \cdot 17$ & 1.89 & $-205 \cdot 30$ & 1.48 & $-195 \cdot 81$ & 2.47 & 0.05 \\
\hline GPX (mU/mg protein) & 3179 & 164 & 3080 & 158 & 3094 & 111 & 2545 & 216 & 0.13 \\
\hline GR (mU/mg protein) & 101.5 & 3.9 & $103 \cdot 3$ & $5 \cdot 8$ & $101 \cdot 6$ & $4 \cdot 1$ & $99 \cdot 2$ & 2.5 & 0.97 \\
\hline GST (mU/mg protein) & 3926 & 388 & $4698 \cdot 76$ & 363 & 4128 & 316 & 3502 & 252 & 0.19 \\
\hline
\end{tabular}

* Data were analysed using a one-way ANOVA, and all significant differences among means at the level of $P<0.05$ were tested with the Tukey-Kramer post hoc analysis. $\dagger$ Redox potential $\left(E_{\mathrm{hc}}\right)$, referring to the half-cell reduction potential of the GSSG/2GSH couple, was calculated using the Nernst equation $\left(25^{\circ} \mathrm{C} \text {, pH } 7 \cdot 0\right)^{(60)}$. 

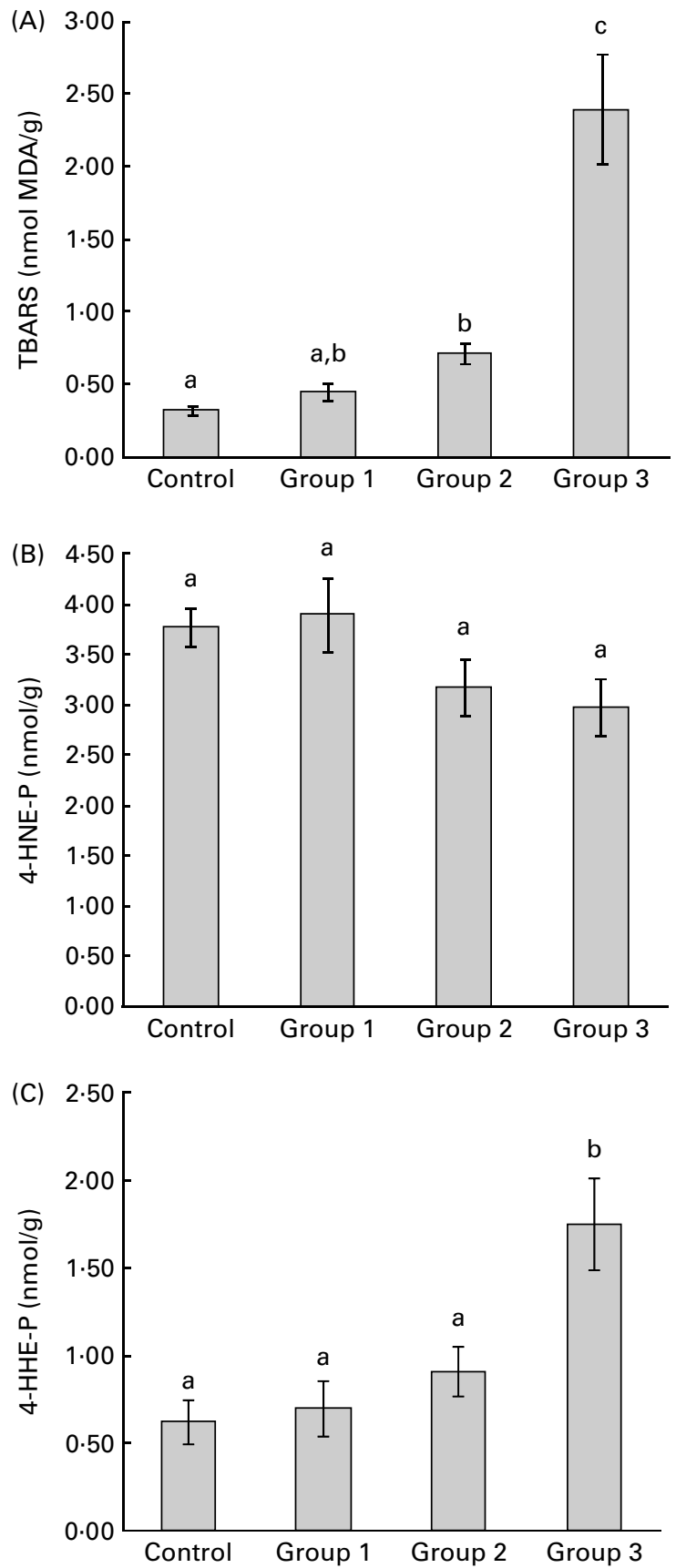

Fig. 1. Dose-response effects of dietary long-chain $n$-3 PUFA on lipoperoxidation measured as (A) thiobarbituric acid-reactive substances (TBARS), a general biomarker of lipoperoxidation, and thioether aldehyde-protein adducts, namely (B) 4-hydroxynonenal-protein (4-HNE-P) and (C) 4-hydroxyhexenal-protein (4-HHE-P), by-products issued specifically from peroxidation of $n-6$ PUFA and $n-3$ PUFA, respectively. Values are means (six to eight animals per group), with standard errors represented by vertical bars. Data were analysed using a one-way ANOVA, and all significant differences among means at the level of $P<0.05$ were tested with the Tukey-Kramer post hoc analysis. ${ }^{\mathrm{a}, \mathrm{b}, \mathrm{c}}$ Mean values with unlike letters were significantly different $(P<0.05)$. MDA, malondialdehyde.

peroxidisability index determined in liver phospholipids (Table 2), lipid peroxidation was substantially increased in a dose-dependent manner in the liver of rabbits given the tuna oil supplements (Fig. 2). TBARS concentration rose by
38, 119 and $632 \%$ in groups 1, 2 and 3, respectively. This dose-response relationship was confirmed by the positive correlation between LC $n-3$ PUFA incorporation into liver phospholipids and the levels of TBARS $\left(r^{2} 0.65, P<0.0001\right.$; Fig. 2). The analysis of specific metabolites produced from $n-6$ and $n-3$ PUFA peroxidation, namely 4-HNE-P and 4-HHE-P, was also performed. Because of the high reactivity of these molecules as free, we chose to quantify the aldehyde-protein adducts. Fig. 1(B) and (C) shows that lipid peroxidation was mainly associated with n-3 PUFA. Indeed, 4-HHE-P hepatic levels increased by 16, 84 and $227 \%$ in groups 1,2 and 3 , respectively $(P=0.003)$, whereas concentrations of 4-HNE-P were unchanged. In the control group, 4-HNE-P levels were almost ten times higher than 4HHE-P levels and despite the substantial increase in 4-HHE$\mathrm{P}$ levels of group 3, they still remain twice lower than 4-HNE-P levels. Moreover, linear regression presented in Fig. 2 shows that the hepatic contents of LC $n$ - 3 PUFA phospholipids were positively correlated with those of 4-HHE-P $\left(r^{2} \quad 0.48, \quad P=0.001\right)$, suggesting again a dose-dependent response; however, only group 3 was significantly different from the control group. Overall, Figs. 1 and 2 show that dietary LC $n-3$ PUFA led to a raised level of lipoperoxidation, essentially due to $n$-3 PUFA peroxidation without significant modification of $n-6$ PUFA peroxidation. Finally, the positive correlations existing between dietary LC $n-3$ PUFA and their incorporation into liver phospholipids $\left(r^{2} 0 \cdot 97\right.$, data not shown), and LC $n$-3 PUFA incorporation into liver phospholipids and the production of TBARS and 4-HHE-P, both confirm the dose-dependent relationships between the intake of LC $n-3$ PUFA and liver lipoperoxidation.

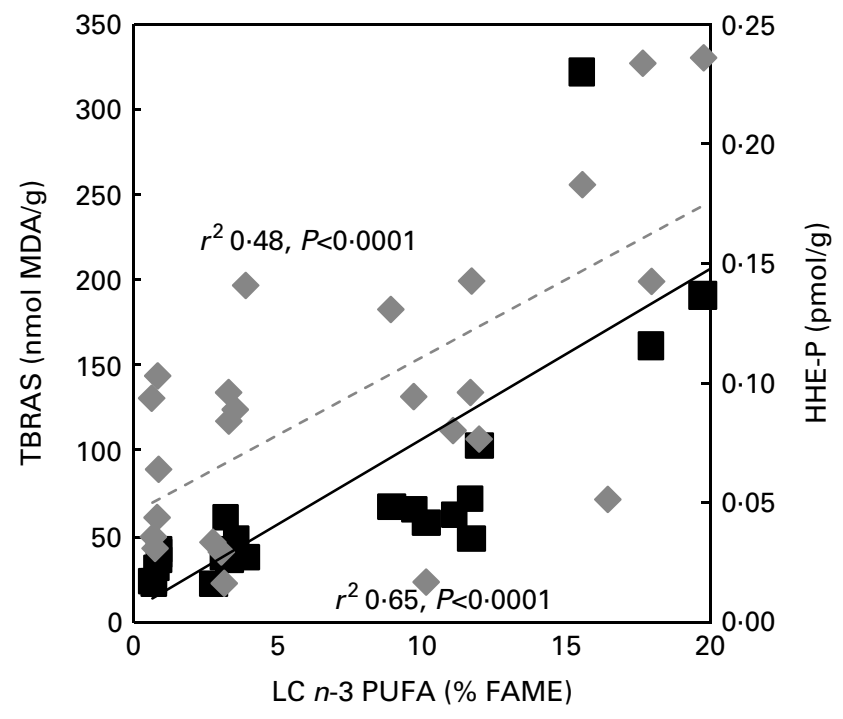

Fig. 2. Correlations between long-chain (LC) $n$-3 PUFA incorporation into liver phospholipids and lipoperoxidation biomarkers. Correlation coefficients between a set of data correspond to the Pearson coefficient $(r)$ and were calculated using GraphPad InStat version 3.06 (GraphPad Software, San Diego, CA, USA; www.graphpad.com). TBARS, thiobarbituric acidreactive substances; MDA, malondialdehyde; FAME, fatty acid methyl esters; HHE-P, hydroxyhexenal-protein. 


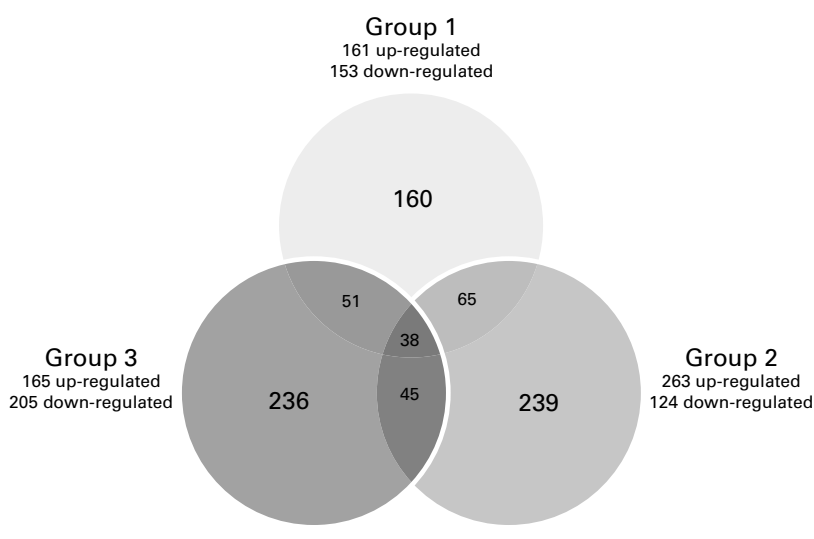

Fig. 3. Venn diagram of significantly differentially expressed genes in groups 1,2 and 3 , providing $0.1,0.5$ and $1 \%$ of daily energy intake as DHA, respectively.

\section{Effects of long-chain n-3 PUFA on liver gene expression}

Global gene expression changes in the liver of rabbits fed the three different doses of LC $n-3$ PUFA were compared with control rabbits. The microarray analyses revealed 314, 387 and 370 genes differently expressed ( $\mathrm{FC} \geq 1 \cdot 2, P<0.05)$ in groups 1, 2 and 3, respectively. As shown in the Venn diagram (Fig. 3), thirty-eight genes were common between the three groups. Most genes had increased levels of expression with LC $n$-3 PUFA except with dose 3 where mRNA levels of hepatic genes were mostly reduced. The uploading of datasets into IPA reveals that more than $80 \%$ of genes differentially expressed were eligible for network generation and most of them were also associated with pathways and functions.

Differentially expressed genes were classified into GO categories. The top ten GO classifications for biological processes for the three groups are represented in Fig. 4. As shown in the overlapping circles, groups 1 and 2 shared almost half of the identified biological processes and most of them were associated with lipid metabolism: lipid transport, steroid metabolism, lipid metabolism, sterol biosynthesis, steroid biosynthesis, lipid biosynthesis and sterol metabolism. Group 3 is differentiated by the low number of biological processes in common with groups 1 and 2 and the absence of links with lipid metabolism. The most over-represented biological processes in group 3 are related to urea metabolism and blood coagulation.

The top ten metabolic and signalling pathways showing significant changes in gene expression levels for the three experimental groups are reported in Fig. 5 and Table 5. Pathways related to inflammation and coagulation were over-represented in all groups, whereas lipid metabolism pathways were only associated with groups 1 and 2. Pathways related to energy metabolism were also well represented in all groups.

Effects of long-chain n-3 PUFA on inflammation. The 'acute-phase response signalling' pathway is one of the most significant pathways associated with datasets. It is also one of the top three pathways in the three groups. Interestingly, the association of this pathway to the dataset increases with the dose of LC $n-3$ PUFA. Among the twenty-three genes differently expressed, three were common between the three groups. These included the serine peptidase inhibitors serpin peptidase inhibitor, clade A ( $\alpha 1$ antiproteinase, antitrypsin), member 1 (SERPINA1) and serpin peptidase inhibitor, clade D (heparin cofactor), member 1 (SERPIND1) genes as well as the suppressor of cytokine signalling. Some of the genes, whose abundance was significantly modulated, include gene-encoding proteins involved in signal transduction such as v-Ki-ras2 Kirsten rat sarcoma viral oncogene homologue, mitogen-activated protein kinase kinase 4 and Neuroblastoma RAS viral (v-ras) oncogene homologue. Other molecules were specific to either group 1, 2 or 3. In group 1, the expression level of protease inhibitor and cytokine transporter $\alpha 2$-macroglobulin genes was lowered in comparison with the control group. The abundance of several genes was specifically changed in group 2. Among them, the reduced expression

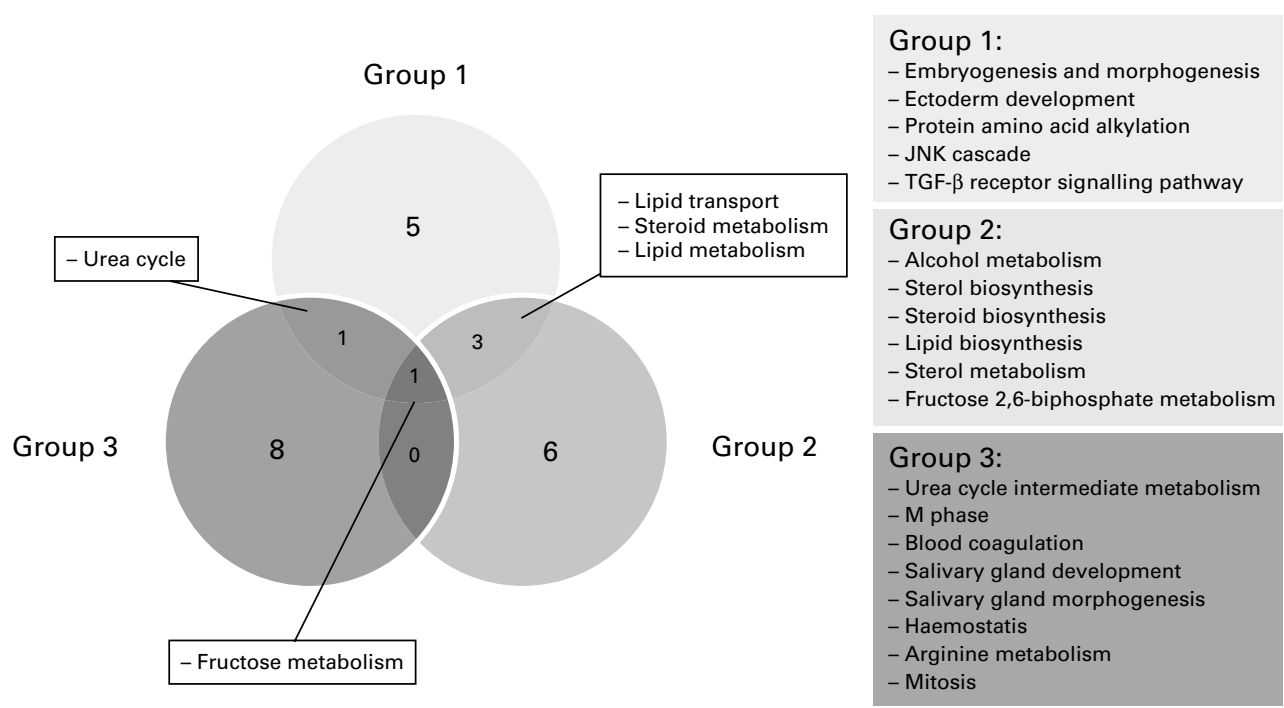

Fig. 4. Venn diagram depicting the top ten Gene Ontology (GO) classifications for biological processes and indicating the specificities and the commonalities (overlapping circles) between the three groups. JNK, c-Jun $\mathrm{NH}_{2}$-terminal kinase; TGF- $\beta$, transforming growth factor- $\beta$. 

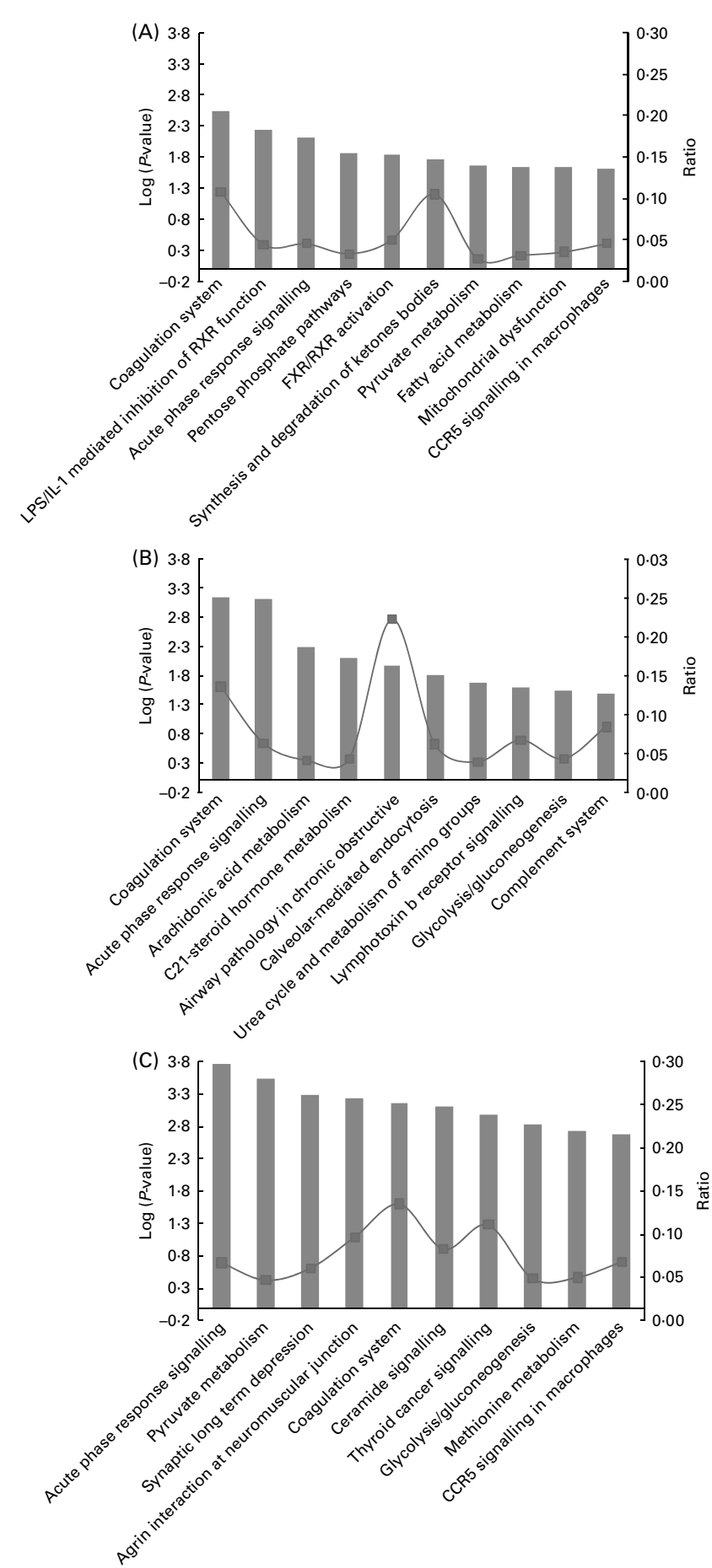

Fig. 5. Top ten canonical pathways significantly modulated in $(A)$ group 1, (B) group 2 and (C) group 3. 'Ratio' indicates the number of molecules in a given pathway that meet cut-off criteria, divided by the total number of molecules that make up that pathway. $P$ value is calculated using the right-tailed Fisher's exact test. LPS, lipopolysaccharide; RXR, retinoid X receptor; FXR, farnesol $X$ receptor.

levels of the TNF receptor TNF receptor superfamily, member $11 \mathrm{~b}$ gene and the increased expression levels of ApoA2 and kallikrein B, plasma (Fletcher factor) 1 (KLKB1) genes are directly linked to the inflammatory response. Other genes significantly modulated in group 2 were associated with the regulation of gene transcription such as v-fos FBJ murine osteosarcoma viral oncogene homologue and nuclear factor of kappa light polypeptide gene enhancer in B-cells inhibitor, $\alpha$, a member of the IкB family, whose abundance was increased. In group 3, the expression levels of the gene coding for the major inflammatory protein C-reactive protein were substantially lowered and the transcription factor Jun oncogene was up-regulated.

Among the top ten pathways of groups 1, 2 and 3, other pathways were linked to inflammation such as 'CCR5 signalling in macrophages', airway pathology in chronic obstructive disease', 'calveolar-mediated endocytosis', 'lymphotoxin b-receptor signalling', 'thyroid cancer signalling' and 'complement system'. They were mainly associated with group 2 and contain genes directly related to inflammation such as the chemokine ligands chemokine $(\mathrm{C}-\mathrm{X}-\mathrm{C}$ motif) ligand 3 (CXCL3) and chemokine (C-C motif) ligand 4 (CCL4), the interleukin IL- 8 , the integrins integrin, $\alpha \mathrm{D}$, integrin, $\alpha \mathrm{V}$ (vitronectin receptor, $\alpha$ polypeptide, antigen CD51) and integrin, $\beta$ 5, and the TNF-associated factor TNF receptor-associated factor 3. Moreover, the top first networks generated from the overall datasets of groups 1, 2 and 3 were all characterised by a common main central node: the NFкB complex, a major transcription factor involved in inflammation.

Effect of long long-chain n-3 PUFA on coagulation. The 'coagulation system' was the second common pathway between the three groups. The serine protease inhibitors SERPINA1 and SERPIND1, also found in the acute-phase response signalling' pathway, were the only genes in common between groups 1, 2 and 3. These serine protease inhibitors, together with serpin peptidase inhibitor, clade C (antithrombin), member 1 ( $\mathrm{FC}=-1.30$ in group 3 ), are all involved in the inhibition of the F2A factor (thrombin). In group 2, the mRNA levels of two coagulation factors were significantly increased: the coagulation factor III, also known as the tissue factor, and KLKB1, also known as the Fletcher factor, both of which are involved in the initiation of coagulation. In group 3, these factors were unchanged but the subunit $\mathrm{B}$ of the coagulation factor XIII was significantly down-regulated (FC $=-1.55)$.

Effects of long long-chain n-3 PUFA on lipid metabolism. Among all the pathways significantly modulated by LC $n-3$ PUFA, three were directly in relation to the metabolism of lipids. These include 'fatty acid metabolism' (top 8 pathway for group 1), 'arachidonic acid metabolism' (top 3 pathway for group 2) and 'FXR/retinoid X receptor activation' (top 5 pathway for group 2). In the 'fatty acid metabolism' pathway, there were significant changes in several genes coding for the enzymes such as acetyl-CoA acetyltransferase 2, acyl-CoA oxidase 2, acyl-CoA synthetases such as acyl-CoA synthetase long-chain family member 3 , and hydroxyacyl-CoA dehydrogenase. The 'arachidonic acid metabolism' pathway was mainly modulated in group 2. Basically, in group 2, there was an inhibition of the arachidonate metabolism via the reduced mRNA levels of unspecified mono-oxygenases (cytochrome $\mathrm{P} 450$, family 2, subfamily C, polypeptide 18 and cytochrome $\mathrm{P} 450$, family 4 , subfamily $\mathrm{B}$, polypeptide 1 ) and PG synthase PG E synthase 3 genes. LC $n-3$ PUFAdose 2 also induced the expression of the detoxification 


\section{N British Journal of Nutrition}

Table 5. Top 10 metabolic and signalling pathways significantly modulated in each comparison: control $v$. group 1 , control $v$. group 2 and control $v$. group 3 ; the doses of DHA in the three different groups being $0.1,0.5$ and $1 \%$ of daily energy intake, respectively

\begin{tabular}{|c|c|c|c|c|c|c|c|c|}
\hline \multirow[b]{2}{*}{ Gene symbol } & \multirow[b]{2}{*}{ Gene description } & \multirow{2}{*}{$\begin{array}{l}\text { Entrez } \\
\text { gene ID }\end{array}$} & \multicolumn{2}{|c|}{$\begin{array}{c}\text { Control } v \text {. group } \\
1\end{array}$} & \multicolumn{2}{|c|}{ Control v. group 2} & \multicolumn{2}{|c|}{ Control $v$. group 3} \\
\hline & & & FC & $P$ & FC & $P$ & FC & $P$ \\
\hline \multicolumn{9}{|c|}{ Acute-phase response signalling } \\
\hline A2M & a2-Macroglobulin & 2 & -1.44 & 0.027 & & & & \\
\hline AKT2 & v-akt murine thymoma viral oncogene homologue 2 & 208 & & & 1.29 & 0.042 & & \\
\hline АроA2 & apoA-II & 336 & & & 1.99 & 0.038 & & \\
\hline C9 & Complement component 9 & 735 & & & -1.45 & 0.046 & -1.73 & 0.011 \\
\hline CRP (includes EG:1401) & C-reactive protein, pentraxin-related & 1401 & & & & & -2.31 & 0.026 \\
\hline FOS & v-fos FBJ murine osteosarcoma viral oncogene homologue & 2353 & & & 2.48 & 0.017 & & \\
\hline$H P X$ & Haemopexin & 3263 & & & & & -1.6 & 0.015 \\
\hline$H R G$ & Histidine-rich glycoprotein & 3273 & & & & & 1.41 & 0.041 \\
\hline JUN & Jun oncogene & 3725 & & & & & 1.35 & 0.020 \\
\hline KLKB1 & Kallikrein B, plasma (Fletcher factor) 1 & 3818 & & & 1.68 & 0.004 & & \\
\hline KRAS & v-Ki-ras2 Kirsten rat sarcoma viral oncogene homologue & 3845 & 1.44 & 0.040 & & & 1.45 & 0.030 \\
\hline MAP2K4 & Mitogen-activated protein kinase kinase 4 & 6416 & -1.23 & 0.040 & & & -1.24 & 0.028 \\
\hline MBL2 & Mannose-binding lectin (protein C) 2, soluble (opsonic defect) & 4153 & -1.51 & 0.038 & -1.45 & 0.036 & & \\
\hline NFKBIA & $\begin{array}{l}\text { Nuclear factor of kappa light polypeptide gene enhancer in B-cells } \\
\text { inhibitor, } \alpha\end{array}$ & 4792 & & & 1.35 & 0.020 & & \\
\hline NRAS & Neuroblastoma RAS viral (v-ras) oncogene homologue & 4893 & $1 \cdot 20$ & 0.020 & & & 1.34 & 0.001 \\
\hline SERPINA1 & $\begin{array}{l}\text { Serpin peptidase inhibitor, clade } \mathrm{A} \text { ( } \alpha 1 \text { antiproteinase, antitrypsin), } \\
\text { member } 1\end{array}$ & 5265 & $-1 \cdot 25$ & 0.037 & $-1 \cdot 24$ & 0.026 & -1.57 & $<0.001$ \\
\hline SERPIND1 & Serpin peptidase inhibitor, clade D (heparin cofactor), member 1 & 3053 & -1.49 & 0.001 & -1.42 & 0.001 & -1.31 & 0.012 \\
\hline SERPINF1 & $\begin{array}{l}\text { Serpin peptidase inhibitor. clade } F(\alpha 2 \text { antiplasmin, pigment } \\
\text { epithelium-derived factor), member } 1\end{array}$ & 5176 & & & & & -1.53 & 0.023 \\
\hline SERPINF2 & $\begin{array}{l}\text { Serpin peptidase inhibitor, clade } F(\alpha 2 \text { antiplasmin, pigment } \\
\text { epithelium-derived factor), member } 2\end{array}$ & 5345 & & & $-1 \cdot 24$ & 0.039 & & \\
\hline SOCS5 & Suppressor of cytokine signalling 5 & 9655 & -1.42 & 0.046 & & & & \\
\hline socs6 & Suppressor of cytokine signalling 6 & 9306 & 1.12 & 0.029 & 1.14 & 0.007 & 1.26 & $<0.001$ \\
\hline TNFRSF11B & TNF receptor superfamily, member $11 \mathrm{~b}$ & 4982 & & & -1.43 & 0.022 & & \\
\hline TTR & Transthyretin & 7276 & -1.34 & 0.019 & & & & \\
\hline \multicolumn{9}{|c|}{ Agrin interactions at neuromuscular junction } \\
\hline ACTB & Actin, $\beta$ & 60 & & & & & 1.47 & 0.038 \\
\hline ACTC1 & Actin, $\alpha$, cardiac muscle 1 & 70 & & & & & -1.43 & 0.048 \\
\hline ERBB2 & $\begin{array}{l}\text { v-erb-b2 erythroblastic leukaemia viral oncogene homologue } 2, \\
\text { neuro/glioblastoma-derived oncogene homologue (avian) }\end{array}$ & 2064 & $1 \cdot 24$ & 0.005 & $1 \cdot 15$ & 0.023 & $1 \cdot 26$ & 0.021 \\
\hline JUN & Jun oncogene & 3725 & & & & & 1.35 & 0.020 \\
\hline KRAS & v-Ki-ras2 Kirsten rat sarcoma viral oncogene homologue & 3845 & 1.44 & 0.040 & & & 1.45 & 0.030 \\
\hline MAP2K4 & Mitogen-activated protein kinase kinase 4 & 6416 & -1.23 & 0.040 & & & -1.24 & 0.028 \\
\hline NRAS & Neuroblastoma RAS viral (v-ras) oncogene homologue & 4893 & $1 \cdot 20$ & 0.020 & & & 1.34 & $<0.001$ \\
\hline \multicolumn{9}{|c|}{ Airway pathology in chronic obstructive pulmonary disease } \\
\hline CXCL3 & Chemokine ( $\mathrm{C}-\mathrm{X}-\mathrm{C}$ motif) ligand 3 & 2921 & & & $2 \cdot 61$ & 0.011 & & \\
\hline IL-8 & & 3576 & & & $3 \cdot 88$ & 0.036 & & \\
\hline \multicolumn{9}{|l|}{ Arachidonic acid metabolism } \\
\hline ACSS2 & Acyl-CoA synthetase short-chain family member 2 & 55902 & & & 1.46 & 0.022 & & \\
\hline CBR3 & Carbonyl reductase 3 & 874 & & & 1.66 & 0.031 & & \\
\hline CYP2C18 & Cytochrome P450, family 2, subfamily C, polypeptide 18 & 1562 & & & -1.69 & 0.005 & & \\
\hline CYP2C9 & Cytochrome P450, family 2, subfamily C, polypeptide 9 & 1559 & -1.74 & 0.045 & & & & \\
\hline CYP4B1 & Cytochrome P450, family 4 , subfamily B, polypeptide 1 & 1580 & & & -2.25 & 0.018 & -2.04 & 0.048 \\
\hline CYP51A1 & Cytochrome P450, family 51, subfamily A, polypeptide 1 & 1595 & & & 1.27 & 0.009 & & \\
\hline
\end{tabular}




\begin{tabular}{|c|c|c|c|c|c|c|c|c|}
\hline \multirow[b]{2}{*}{ Gene symbol } & \multirow[b]{2}{*}{ Gene description } & \multirow{2}{*}{$\begin{array}{l}\text { Entrez } \\
\text { gene ID }\end{array}$} & \multicolumn{2}{|c|}{$\begin{array}{c}\text { Control v. group } \\
1\end{array}$} & \multicolumn{2}{|c|}{ Control v. group 2} & \multicolumn{2}{|c|}{ Control $v$. group 3} \\
\hline & & & $\mathrm{FC}$ & $P$ & FC & $P$ & FC & $P$ \\
\hline DHRS4 & Dehydrogenase/reductase (SDR family) member 4 & 10901 & -1.57 & 0.028 & -1.58 & 0.023 & & \\
\hline GPX3 & Glutathione peroxidase 3 (plasma) & 2878 & & & & & -2.08 & 0.014 \\
\hline GPX4 & Glutathione peroxidase 4 (phospholipid hydroperoxidase) & 2879 & & & 1.36 & 0.035 & & \\
\hline GRN & Granulin & 2896 & 1.37 & 0.038 & & & & \\
\hline MGST3 & Microsomal glutathione-S-transferase 3 & 4259 & & & & & -1.24 & 0.037 \\
\hline PLA2G4A & Phospholipase A2, group IVA (cytosolic, calcium-dependent) & 5321 & & & & & -1.22 & 0.009 \\
\hline PLOD1 & Procollagen-lysine 1, 2-oxoglutarate 5-dioxygenase 1 & 5351 & 1.28 & 0.039 & & & & \\
\hline PNPLA3 & Patatin-like phospholipase domain containing 3 & 80339 & & & $1 \cdot 35$ & 0.014 & 1.35 & 0.021 \\
\hline PTGES3 (includes EG:10728) & Prostaglandin E synthase 3 (cytosolic) & 10728 & & & -1.25 & 0.025 & & \\
\hline \multicolumn{9}{|l|}{ C21-steroid hormone metabolism } \\
\hline HSD11B1 & Hydroxysteroid $(11-\beta)$ dehydrogenase 1 & 3290 & -1.47 & 0.015 & -1.37 & 0.019 & & \\
\hline HSD17B2 & Hydroxysteroid $(17-\beta)$ dehydrogenase 2 & 3294 & & & -1.23 & 0.037 & & \\
\hline NSDHL & NAD(P)-dependent steroid dehydrogenase-like & 50814 & & & 1.35 & 0.007 & & \\
\hline \multicolumn{9}{|l|}{ Caveolar-mediated endocytosis } \\
\hline ACTB & Actin, $\beta$ & 60 & & & & & 1.47 & 0.038 \\
\hline ACTC1 & Actin, $\alpha$, cardiac muscle 1 & 70 & & & & & -1.43 & 0.048 \\
\hline FLNC & Filamin C, $\gamma$ (actin-binding protein 280$)$ & 2318 & & & -1.30 & 0.013 & & \\
\hline$H L A-C$ & MHC, class I, C & 3107 & & & 1.86 & 0.037 & & \\
\hline ITGAD & Integrin, $\alpha \mathrm{D}$ & 3681 & 1.80 & 0.039 & 1.69 & 0.033 & & \\
\hline ITGAV & Integrin, $\alpha \mathrm{V}$ (vitronectin receptor, $\alpha$ polypeptide, antigen CD51) & 3685 & & & $2 \cdot 27$ & 0.004 & & \\
\hline ITGB5 & Integrin, $\beta 5$ & 3693 & & & 1.89 & 0.026 & & \\
\hline PRKCA & Protein kinase $\mathrm{C}_{\alpha}$ & 5578 & & & & & -1.22 & 0.006 \\
\hline \multicolumn{9}{|l|}{ CCR5 signalling in macrophages } \\
\hline CCL4 & Chemokine (C-C motif) ligand 4 & 6351 & & & 1.73 & 0.024 & & \\
\hline CD247 & CD247 molecule & 919 & $-1 \cdot 21$ & 0.041 & & & -1.29 & 0.009 \\
\hline$C D 3 D$ & CD3d molecule, delta (CD3-TCR complex) & 915 & & & & & -1.41 & 0.049 \\
\hline FOS & v-fos FBJ murine osteosarcoma viral oncogene homologue & 2353 & & & 2.48 & 0.017 & & \\
\hline GNAl1 & $\begin{array}{l}\text { Guanine nucleotide-binding protein (G protein), } \alpha \text {-inhibiting activity } \\
\text { polypeptide } 1\end{array}$ & 2770 & $1 \cdot 26$ & 0.049 & & & & \\
\hline GNAI3 & $\begin{array}{l}\text { Guanine nucleotide-binding protein (G protein), } \alpha \text {-inhibiting activity } \\
\text { polypeptide } 3\end{array}$ & 2773 & $1 \cdot 30$ & 0.006 & & & $1 \cdot 31$ & 0.006 \\
\hline \multicolumn{9}{|l|}{ Ceramide signalling } \\
\hline AKT2 & v-akt murine thymoma viral oncogene homologue 2 & 208 & & & 1.29 & 0.042 & & \\
\hline FOS & v-fos FBJ murine osteosarcoma viral oncogene homologue & 2353 & & & 2.48 & 0.017 & & \\
\hline JUN & Jun oncogene & 3725 & & & & & 1.35 & 0.020 \\
\hline KRAS & v-Ki-ras2 Kirsten rat sarcoma viral oncogene homologue & 3845 & 1.44 & 0.040 & & & 1.45 & 0.030 \\
\hline MAP2K4 & Mitogen-activated protein kinase kinase 4 & 6416 & -1.23 & 0.040 & & & -1.24 & 0.028 \\
\hline NRAS & Neuroblastoma RAS viral (v-ras) oncogene homologue & 4893 & 1.20 & 0.020 & & & 1.34 & 0.008 \\
\hline PPP2R2A & Protein phosphatase 2 (formerly $2 A$ ), regulatory subunit $B, \alpha$ isoform & 5520 & & & & & 1.32 & 0.012 \\
\hline$P P P 2 R 2 B$ & Protein phosphatase 2 (formerly $2 A$ ), regulatory subunit $B, \beta$ isoform & 5521 & & & & & 1.44 & 0.018 \\
\hline PPP2R3A (includes EG:5523) & Protein phosphatase 2 (formerly $2 A$ ), regulatory subunit $B^{\prime \prime}, \alpha$ & 5523 & & & & & 1.21 & 0.035 \\
\hline PPP2R5A & Protein phosphatase 2 , regulatory subunit $\mathrm{B}^{\prime}, \alpha$ isoform & 5525 & $-1 \cdot 26$ & 0.019 & $-1 \cdot 20$ & 0.033 & & \\
\hline TNFRSF11B & TNF receptor superfamily, member $11 \mathrm{~b}$ & 4982 & & & -1.43 & 0.022 & & \\
\hline \multicolumn{9}{|l|}{ Coagulation system } \\
\hline A2M & $\alpha$-2-Macroglobulin & 2 & -1.44 & 0.027 & & & & \\
\hline$F 13 B$ & Coagulation factor XIII, B polypeptide & 2165 & & & & & -1.55 & 0.007 \\
\hline F3 & Coagulation factor III (thromboplastin, tissue factor) & 2152 & & & 1.86 & 0.017 & & \\
\hline
\end{tabular}




\begin{tabular}{|c|c|c|c|c|c|c|c|c|}
\hline \multirow[b]{2}{*}{ Gene symbol } & \multirow[b]{2}{*}{ Gene description } & \multirow{2}{*}{$\begin{array}{c}\text { Entrez } \\
\text { gene ID }\end{array}$} & \multicolumn{2}{|c|}{$\begin{array}{c}\text { Control } v \text {. group } \\
1\end{array}$} & \multicolumn{2}{|c|}{ Control v. group 2} & \multicolumn{2}{|c|}{ Control $v$. group 3} \\
\hline & & & FC & $P$ & FC & $P$ & FC & $P$ \\
\hline KLKB1 & Kallikrein B, plasma (Fletcher factor) 1 & 3818 & & & 1.68 & 0.004 & & \\
\hline KNG1 (includes EG:3827) & Kininogen 1 & 3827 & -1.23 & 0.017 & & & -1.44 & 0.008 \\
\hline SERPINA1 & $\begin{array}{l}\text { Serpin peptidase inhibitor, clade } A \text { ( } \alpha-1 \text { antiproteinase, antitrypsin), } \\
\text { member } 1\end{array}$ & 5265 & -1.25 & 0.037 & -1.24 & 0.026 & -1.57 & $<0.001$ \\
\hline SERPINC1 & Serpin peptidase inhibitor, clade C (antithrombin), member 1 & 462 & & & & & -1.30 & 0.002 \\
\hline SERPIND1 & Serpin peptidase inhibitor, clade D (heparin cofactor), member 1 & 3053 & -1.49 & 0.001 & -1.42 & 0.001 & -1.31 & 0.012 \\
\hline SERPINF2 & $\begin{array}{l}\text { Serpin peptidase inhibitor, clade } F(\alpha-2 \text { antiplasmin, pigment } \\
\text { epithelium-derived factor), member } 2\end{array}$ & 5345 & & & $-1 \cdot 24$ & 0.039 & & \\
\hline \multicolumn{9}{|l|}{ Complement system } \\
\hline C1QA & Complement component 1 , q subcomponent, A chain & 712 & & & 1.39 & 0.046 & & \\
\hline C3AR1 & Complement component 3a receptor 1 & 719 & & & & & -1.25 & 0.017 \\
\hline C9 & Complement component 9 & 735 & & & -1.45 & 0.046 & -1.73 & 0.011 \\
\hline$M B L 2$ & Mannose-binding lectin (protein C) 2, soluble (opsonic defect) & 4153 & -1.51 & 0.038 & -1.45 & 0.036 & & \\
\hline \multicolumn{9}{|l|}{ Fatty acid metabolism } \\
\hline ACAT2 & Acetyl-coenzyme A acetyltransferase 2 & 39 & -1.30 & 0.045 & & & -1.42 & 0.010 \\
\hline ACOX2 & Acyl-coenzyme A oxidase 2, branched chain & 8309 & -1.57 & 0.033 & & & & \\
\hline ACSL1 & Acyl-CoA synthetase long-chain family member 1 & 2180 & -1.28 & 0.041 & & & & \\
\hline ACSL3 & Acyl-CoA synthetase long-chain family member 3 & 2181 & & & 1.57 & 0.011 & 1.66 & 0.009 \\
\hline ACSL5 & Acyl-CoA synthetase long-chain family member 5 & 51703 & -1.36 & 0.019 & & & & \\
\hline CYP2C18 & Cytochrome P450, family 2, subfamily C, polypeptide 18 & 1562 & & & -1.69 & 0.005 & & \\
\hline CYP2C9 & Cytochrome P450, family 2 , subfamily C, polypeptide 9 & 1559 & -1.74 & 0.045 & & & & \\
\hline CYP4B1 & Cytochrome P450, family 4, subfamily B, polypeptide 1 & 1580 & & & $-2 \cdot 25$ & 0.018 & -2.04 & 0.048 \\
\hline CYP51A1 & Cytochrome P450, family 51 , subfamily A, polypeptide 1 & 1595 & & & 1.27 & 0.009 & & \\
\hline DHRS9 & Dehydrogenase/reductase (SDR family) member 9 & 10170 & & & & & -1.77 & 0.002 \\
\hline$H A D H$ & Hydroxyacyl-Coenzyme A dehydrogenase & 3033 & $-1 \cdot 26$ & 0.037 & & & & \\
\hline$H A D H B$ & $\begin{array}{l}\text { Hydroxyacyl-Coenzyme A dehydrogenase/3-ketoacyl-Coenzyme A } \\
\text { thiolase/enoyl-Coenzyme A hydratase (trifunctional protein), } \beta \\
\text { subunit }\end{array}$ & 3032 & & & & & $-1 \cdot 28$ & 0.019 \\
\hline \multicolumn{9}{|l|}{ FXR/RXR activation } \\
\hline ABCB4 & ATP-binding cassette, sub-family B (MDR/TAP), member 4 & 5244 & & & 1.74 & 0.031 & & \\
\hline AKT2 & v-akt murine thymoma viral oncogene homologue 2 & 208 & & & 1.29 & 0.042 & & \\
\hline CYP8B1 & Cytochrome P450, family 8, subfamily B, polypeptide 1 & 1582 & -1.51 & 0.048 & & & & \\
\hline FBP1 & Fructose-1,6-bisphosphatase 1 & 2203 & -1.44 & 0.016 & & & -1.37 & 0.003 \\
\hline MAP2K4 & Mitogen-activated protein kinase kinase 4 & 6416 & -1.23 & 0.040 & & & -1.24 & 0.028 \\
\hline MTTP & Microsomal TAG transfer protein & 4547 & -1.52 & 0.033 & -1.40 & 0.046 & & \\
\hline SULT2A1 & $\begin{array}{l}\text { Sulfotransferase family, cytosolic, 2A, dehydroepiandrosterone- } \\
\text { preferring, member } 1\end{array}$ & 6822 & & & & & -1.52 & 0.001 \\
\hline UGT2B4 & UDP glucuronosyltransferase 2 family, polypeptide B4 & 7363 & & & & & 1.41 & 0.046 \\
\hline$V L D L R$ & VLDL receptor & 7436 & 1.65 & 0.008 & 1.61 & 0.006 & 2.93 & $<0.001$ \\
\hline \multicolumn{9}{|l|}{ Glycolysis/gluconeogenesis } \\
\hline ACSL1 & Acyl-CoA synthetase long-chain family member 1 & 2180 & -1.28 & 0.041 & & & & \\
\hline ACSL3 & Acyl-CoA synthetase long-chain family member 3 & 2181 & & & 1.57 & 0.011 & 1.66 & 0.009 \\
\hline ACSS2 & Acyl-CoA synthetase short-chain family member 2 & 55902 & & & 1.46 & 0.022 & & \\
\hline ACYP2 & Acylphosphatase 2 , muscle type & 98 & & & & & 1.20 & 0.036 \\
\hline$A L D O A$ & Aldolase A, fructose-bisphosphate & 226 & & & -1.24 & 0.043 & & \\
\hline$A L D O B$ & Aldolase $\mathrm{B}$, fructose-bisphosphate & 229 & -1.51 & 0.035 & & & & \\
\hline ALDOC & Aldolase $\mathrm{C}$, fructose-bisphosphate & 230 & & & $-1 \cdot 14$ & 0.040 & $-1 \cdot 21$ & 0.008 \\
\hline
\end{tabular}




\begin{tabular}{|c|c|c|c|c|c|c|c|c|}
\hline \multirow[b]{2}{*}{ Gene symbol } & \multirow[b]{2}{*}{ Gene description } & \multirow{2}{*}{$\begin{array}{c}\text { Entrez } \\
\text { gene ID }\end{array}$} & \multicolumn{2}{|c|}{$\begin{array}{c}\text { Control } v \text {. group } \\
1\end{array}$} & \multicolumn{2}{|c|}{ Control $v$. group 2} & \multicolumn{2}{|c|}{ Control $v$. group 3} \\
\hline & & & $\mathrm{FC}$ & $P$ & $\mathrm{FC}$ & $P$ & $\mathrm{FC}$ & $P$ \\
\hline DHRS9 & Dehydrogenase/reductase (SDR family) member 9 & 10170 & & & & & -1.77 & 0.002 \\
\hline DLAT & Dihydrolipoamide S-acetyltransferase & 1737 & 1.19 & 0.041 & 1.22 & 0.023 & $1 \cdot 18$ & 0.040 \\
\hline FBP1 & Fructose-1,6-bisphosphatase 1 & 2203 & -1.44 & 0.002 & & & -1.37 & 0.003 \\
\hline FBP2 & Fructose-1,6-bisphosphatase 2 & 8789 & -1.46 & 0.004 & & & -1.32 & 0.018 \\
\hline$\angle D H B$ & Lactate dehydrogenase B & 3945 & & & 1.95 & 0.030 & & \\
\hline PGAM1 & Phosphoglycerate mutase 1 (brain) & 5223 & & & & & -1.25 & 0.032 \\
\hline$R W D D 2 A$ & RWD domain containing $2 \mathrm{~A}$ & 112611 & & & 1.22 & 0.031 & & \\
\hline \multicolumn{9}{|c|}{ LPS/IL-1-mediated inhibition of RXR function } \\
\hline ACOX2 & Acyl-Coenzyme A oxidase 2, branched chain & 8309 & -1.57 & 0.033 & & & & \\
\hline ACSL1 & Acyl-CoA synthetase long-chain family member 1 & 2180 & $-1 \cdot 28$ & 0.041 & & & & \\
\hline ACSL3 & Acyl-CoA synthetase long-chain family member 3 & 2181 & & & 1.57 & 0.011 & 1.66 & 0.009 \\
\hline ACSL5 & Acyl-CoA synthetase long-chain family member 5 & 51703 & -1.36 & 0.019 & & & & \\
\hline CAT & Catalase & 847 & -1.58 & 0.049 & & & & \\
\hline CYP2C9 & Cytochrome P450, family 2, subfamily C, polypeptide 9 & 1559 & -1.74 & 0.045 & & & & \\
\hline GSTM5 & Glutathione $S$-transferase mu 5 & 2949 & -1.50 & 0.043 & & & & \\
\hline HMGCS2 & 3-Hydroxy-3-methylglutaryl-Coenzyme A synthase 2 (mitochondrial) & 3158 & -1.39 & 0.040 & & & & \\
\hline JUN & Jun oncogene & 3725 & & & & & 1.35 & 0.020 \\
\hline MAP2K4 & Mitogen-activated protein kinase kinase 4 & 6416 & -1.23 & 0.040 & & & $-1 \cdot 24$ & 0.028 \\
\hline MGST1 & Microsomal glutathione S-transferase 1 & 4257 & -1.38 & 0.041 & & & & \\
\hline MGST3 & Microsomal glutathione $S$-transferase 3 & 4259 & & & & & $-1 \cdot 24$ & 0.039 \\
\hline SULT2A1 & $\begin{array}{l}\text { Sulfotransferase family, cytosolic, } 2 \mathrm{~A} \text {, dehydroepiandrosterone- } \\
\text { preferring, member } 1\end{array}$ & 6822 & & & & & -1.52 & 0.001 \\
\hline \multicolumn{9}{|l|}{ Lymphotoxin- $\beta$ receptor signalling } \\
\hline AKT2 & v-akt murine thymoma viral oncogene homologue 2 & 208 & & & 1.29 & 0.042 & & \\
\hline CASP3 & Caspase 3 , apoptosis-related cysteine peptidase & 836 & 1.67 & 0.020 & 1.69 & 0.007 & 1.61 & 0.023 \\
\hline NFKBIA & $\begin{array}{l}\text { Nuclear factor of kappa light polypeptide gene enhancer in B-cells } \\
\text { inhibitor, } \alpha\end{array}$ & 4792 & & & 1.35 & 0.020 & & \\
\hline TRAF3 & TNF receptor-associated factor 3 & 7187 & & & $1 \cdot 21$ & 0.023 & & \\
\hline \multicolumn{9}{|l|}{ Methionine metabolism } \\
\hline AGXT2L2 & Alanine-glyoxylate aminotransferase 2 -like 2 & 85007 & $-1 \cdot 20$ & 0.046 & -1.24 & 0.011 & & \\
\hline$A H C Y$ & $S$-Adenosylhomocysteine hydrolase & 191 & & & -1.50 & 0.033 & -1.56 & 0.031 \\
\hline BHMT & Betaine-homocysteine methyltransferase & 635 & -1.94 & 0.010 & -1.73 & 0.014 & -2.02 & 0.006 \\
\hline CTH & Cystathionase (cystathionine $\gamma$-lyase) & 1491 & & & & & $-3 \cdot 72$ & 0.001 \\
\hline MAT2A & Methionine adenosyltransferase II, $\alpha$ & 4144 & & & & & $-1 \cdot 24$ & 0.017 \\
\hline \multicolumn{9}{|l|}{ Mitochondrial dysfunction } \\
\hline AlFM1 & Apoptosis-inducing factor, mitochondrion-associated, 1 & 9131 & & & & & 1.24 & 0.023 \\
\hline CASP3 & Caspase 3 , apoptosis-related cysteine peptidase & 836 & 1.67 & 0.020 & 1.69 & 0.007 & 1.61 & 0.023 \\
\hline CAT & Catalase & 847 & -1.58 & 0.049 & & & & \\
\hline COX6C & Cytochrome $c$ oxidase subunit VIc & 1345 & $1 \cdot 15$ & 0.039 & $1 \cdot 24$ & 0.023 & & \\
\hline COX7B2 (includes EG:170712) & Cytochrome $c$ oxidase subunit VIlb2 & 170712 & & & & & -1.29 & 0.046 \\
\hline GPX4 & Glutathione peroxidase 4 (phospholipid hydroperoxidase) & 2879 & & & 1.36 & 0.035 & & \\
\hline MAP2K4 & Mitogen-activated protein kinase kinase 4 & 6416 & $-1 \cdot 23$ & 0.040 & & & $-1 \cdot 24$ & 0.028 \\
\hline NCSTN & Nicastrin & 23385 & 1.18 & 0.015 & & & 1.25 & 0.002 \\
\hline NDUFA4 & NADH dehydrogenase (ubiquinone) $1 \alpha$ subcomplex, $4,9 \mathrm{kDa}$ & 4697 & 1.26 & 0.030 & 1.16 & 0.004 & & \\
\hline UQCRC1 & Ubiquinol-cytochrome $c$ reductase core protein I & 7384 & -1.97 & 0.025 & -1.90 & 0.017 & & \\
\hline UQCRC2 & Ubiquinol-cytochrome $c$ reductase core protein II & 7385 & $-1 \cdot 28$ & 0.001 & & & $-1 \cdot 15$ & 0.046 \\
\hline
\end{tabular}




\begin{tabular}{|c|c|c|c|c|c|c|c|c|}
\hline \multirow[b]{2}{*}{ Gene symbol } & \multirow[b]{2}{*}{ Gene description } & \multirow{2}{*}{$\begin{array}{l}\text { Entrez } \\
\text { gene ID }\end{array}$} & \multicolumn{2}{|c|}{$\begin{array}{c}\text { Control } v \text {. group } \\
1\end{array}$} & \multicolumn{2}{|c|}{ Control v. group 2} & \multicolumn{2}{|c|}{ Control v. group 3} \\
\hline & & & FC & $P$ & $\mathrm{FC}$ & $P$ & $\mathrm{FC}$ & $P$ \\
\hline \multicolumn{9}{|l|}{ Pentose phosphate pathway } \\
\hline$A L D O A$ & Aldolase A, fructose-bisphosphate & 226 & & & $-1 \cdot 24$ & 0.043 & & \\
\hline$A L D O B$ & Aldolase B, fructose-bisphosphate & 229 & -1.51 & 0.035 & & & & \\
\hline ALDOC & Aldolase $\mathrm{C}$, fructose-bisphosphate & 230 & & & $-1 \cdot 14$ & 0.040 & $-1 \cdot 21$ & 0.008 \\
\hline FBP1 & Fructose-1,6-bisphosphatase 1 & 2203 & -1.44 & 0.002 & & & -1.37 & 0.003 \\
\hline FBP2 & Fructose-1,6-bisphosphatase 2 & 8789 & -1.46 & 0.004 & & & -1.32 & 0.018 \\
\hline \multicolumn{9}{|l|}{ Pyruvate metabolism } \\
\hline ACAT2 & Acetyl-Coenzyme A acetyltransferase 2 & 39 & -1.30 & 0.049 & & & -1.42 & 0.010 \\
\hline ACOT12 & Acyl-CoA thioesterase 12 & 134526 & -1.38 & 0.018 & & & & \\
\hline ACSL1 & Acyl-CoA synthetase long-chain family member 1 & 2180 & $-1 \cdot 28$ & 0.041 & & & & \\
\hline ACSL3 & Acyl-CoA synthetase long-chain family member 3 & 2181 & & & 1.57 & 0.011 & 1.66 & 0.009 \\
\hline ACSS2 & Acyl-CoA synthetase short-chain family member 2 & 55902 & & & 1.46 & 0.019 & & \\
\hline ACYP2 & Acylphosphatase 2, muscle type & 98 & & & & & 1.20 & 0.036 \\
\hline DLAT & Dihydrolipoamide $S$-acetyltransferase & 1737 & 1.19 & 0.041 & 1.22 & 0.023 & 1.18 & 0.040 \\
\hline GLO1 & Glyoxalase I & 2739 & -1.37 & 0.004 & & & -1.32 & 0.006 \\
\hline GRHPR & Glyoxylate reductase/hydroxypyruvate reductase & 9380 & $-1 \cdot 19$ & 0.045 & & & $-1 \cdot 28$ & 0.005 \\
\hline$H A D H B$ & $\begin{array}{l}\text { Hydroxyacyl-Coenzyme A dehydrogenase/3-ketoacyl-Coenzyme A } \\
\text { thiolase/enoyl-Coenzyme A hydratase (trifunctional protein), } \beta \\
\text { subunit }\end{array}$ & 3032 & & & & & $-1 \cdot 28$ & 0.019 \\
\hline$\angle D H B$ & Lactate dehydrogenase B & 3945 & & & 1.95 & 0.030 & & \\
\hline MDH1 & Malate dehydrogenase 1, NAD (soluble) & 4190 & & & & & $-1 \cdot 21$ & 0.014 \\
\hline$R W D D 2 A$ & RWD domain containing $2 \mathrm{~A}$ & 112611 & & & $1 \cdot 22$ & 0.031 & & \\
\hline \multicolumn{9}{|l|}{ Synaptic long-term depression } \\
\hline GNAl1 & $\begin{array}{l}\text { Guanine nucleotide-binding protein (G protein), } \alpha \text { inhibiting activity } \\
\text { polypeptide } 1 \alpha\end{array}$ & 2770 & $1 \cdot 26$ & 0.049 & & & & \\
\hline GNAI3 & $\begin{array}{l}\text { Guanine nucleotide-binding protein (G protein), } \alpha \text { inhibiting activity } \\
\text { polypeptide } 3\end{array}$ & 2773 & 1.31 & 0.006 & & & 1.31 & 0.006 \\
\hline GRN & Granulin & 2896 & 1.37 & 0.038 & & & & \\
\hline GUCY2C & Guanylate cyclase 2C (heat-stable enterotoxin receptor) & 2984 & & & 1.48 & 0.008 & 1.56 & 0.007 \\
\hline KRAS & v-Ki-ras2 Kirsten rat sarcoma viral oncogene homologue & 3845 & 1.44 & 0.040 & & & 1.45 & 0.030 \\
\hline NRAS & Neuroblastoma RAS viral (v-ras) oncogene homologue & 4893 & $1 \cdot 20$ & 0.020 & & & 1.34 & $<0.001$ \\
\hline PLA2G4A & Phospholipase A2, group IVA (cytosolic, calcium-dependent) & 5321 & & & & & $-1 \cdot 22$ & 0.009 \\
\hline PNPLA3 & Patatin-like phospholipase domain containing 3 & 80339 & & & 1.35 & 0.014 & 1.35 & 0.020 \\
\hline PPP2R2A & Protein phosphatase 2 (formerly $2 A$ ), regulatory subunit $B, \alpha$ isoform & 5520 & & & & & 1.32 & 0.012 \\
\hline$P P P 2 R 2 B$ & Protein phosphatase 2 (formerly $2 A$ ), regulatory subunit $B, \beta$ isoform & 5521 & & & & & 1.44 & 0.018 \\
\hline$P P P 2 R 3 A$ (includes EG:5523) & Protein phosphatase 2 (formerly $2 A$ ), regulatory subunit $B^{\prime \prime}, \alpha$ & 5523 & & & & & 1.21 & 0.035 \\
\hline PPP2R5A & Protein phosphatase 2 , regulatory subunit $\mathrm{B}^{\prime}, \alpha$ isoform & 5525 & -1.26 & 0.019 & -1.20 & 0.033 & & \\
\hline$P R K C A$ & Protein kinase $\mathrm{C}, \alpha$ & 5578 & & & & & -1.22 & 0.006 \\
\hline \multicolumn{9}{|c|}{ Synthesis and degradation of ketone bodies } \\
\hline ACAT2 & Acetyl-Coenzyme A acetyltransferase 2 & 39 & -1.30 & 0.045 & & & -1.42 & 0.010 \\
\hline$H A D H B$ & $\begin{array}{l}\text { Hydroxyacyl-Coenzyme A dehydrogenase/3-ketoacyl-Coenzyme A } \\
\text { thiolase/enoyl-Coenzyme A hydratase (trifunctional protein), } \\
\beta \text { subunit }\end{array}$ & 3032 & & & & & $-1 \cdot 28$ & 0.019 \\
\hline HMGCS2 & 3-Hydroxy-3-methylglutaryl-Coenzyme A synthase 2 (mitochondrial) & 3158 & $-1 \cdot 39$ & 0.040 & & & & \\
\hline \multicolumn{9}{|l|}{ Thyroid cancer signalling } \\
\hline BDNF & Brain-derived neurotrophic factor & 627 & & & 1.32 & 0.019 & 1.36 & 0.008 \\
\hline CCND1 & Cyclin D1 & 595 & & & & & -1.59 & 0.047 \\
\hline
\end{tabular}


enzyme glutathione peroxidase 4 gene, which is involved in the metabolism of lipid peroxides. This increase in expression level was not associated with an increase in glutathione peroxidase activity (Table 4). The 'FXR/retinoid $\mathrm{X}$ receptor activation' pathway was the main signalling pathway linked with lipid metabolism altered by LC $n$-3 PUFA. Among the genes whose abundance was significantly changed by LC $n-3$ PUFA, the microsomal TAG transfer protein (MTTP) and the lipoprotein receptor VLDLR are of interest because of their crucial role in lipoprotein metabolism. Their expression level was differently modulated with the three doses of LC $n$-3 PUFA. Indeed, MTTP mRNA level was decreased with doses 1 and 2 but not with dose 3. On the contrary, the abundance of the $V L D L R$ gene was raised in a dosedependent manner, leading to a FC of almost 3 in group 3.

Effects of long long-chain n-3 PUFA on energy metabolism. Several of the top ten pathways in groups 1, 2, and 3 were associated with energy metabolism. These include 'synthesis and degradation of ketone bodies' with the down-regulation of 3-hydroxy-3-methylglutaryl-CoA synthase, 'pyruvate metabolism' and 'glycolysis/gluconeogenesis'.

Specific effects of LC n-3 PUFA-dose 3. As shown in Figs. 1 and 2, group 3 was associated with a significantly increased lipid peroxidation level. As peroxidised metabolites produced from LC $n-3$ PUFA are potential modulators of gene expression, we focused our analysis on genes that were specifically and substantially changed (i.e. FC >1.5) in group 3 (Table 6). Among the thirty-four genes differentially expressed at a FC $>1.5$ or $<-1.5$, ten genes had increased expression levels. Among them, two molecules were once again central in the metabolism of lipoprotein and cholesterol. These include the LDL-receptor (LDLR) that contributes to the uptake of circulating LDL and subsequently to hepatic metabolism of cholesterol. The abundance of the insulin-induced gene 1 was also increased in group 3 . This gene encodes an endoplasmic reticulum membrane protein that plays a critical role in regulating cholesterol concentration in cells. Indeed, insulin-induced gene 1 binds to the sterol-sensing domains of sterol regulatory element-binding protein and 3-hydroxy3-methylglutaryl-CoA reductase and is essential for the sterol-mediating trafficking of the two proteins. It is also interesting to note the increased abundance of the gene coding for ubiquitin-conjugating enzyme (ubiquitin-conjugating enzyme E2T) involved in the proteasome-dependent proteolysis. In group 3, twenty-four genes had decreased levels. These include a serine protease inhibitor (serpin peptidase inhibitor. clade F ( $\alpha 2$ antiplasmin, pigment epithelium-derived factor), member 1) and the coagulation factor XIII genes already described. Other genes altered such as haemopexin, glutathione peroxidase 3 or the metallothioneins (metallothionein 3, Metallothionein 2A, Metallothionein 1X) are directly linked to oxidative stress.

\section{Discussion}

The biological effects of LC $n-3$ PUFA can be mediated in part by their actions at the gene expression level but the complexity of altered biological pathways and the nature of the 
Table 6. List of genes significantly up- and down-regulated at a fold change $>1.5$ or $<-1.5$, only with dose 3 of LC- $n-3$ PUFA (1\% of daily energy intake as DHA)

\begin{tabular}{|c|c|c|c|c|}
\hline Symbol & Entrez gene name & $\begin{array}{l}\text { Entrez } \\
\text { gene ID }\end{array}$ & $\begin{array}{l}\text { Fold } \\
\text { change }\end{array}$ & $P$ \\
\hline TNFSF10 & TNF (ligand) superfamily. member 10 & 8743 & $2 \cdot 25$ & 0.019 \\
\hline WDFY1 & WD repeat and FYVE domain containing 1 & 57590 & 1.99 & 0.031 \\
\hline$B 3 G A L N T 1$ & $\begin{array}{l}\beta-1,3-N-\text { Acetylgalactosaminyltransferase } 1 \\
\quad \text { (globoside blood group) }\end{array}$ & 8706 & 1.98 & 0.046 \\
\hline$U C R C$ & Ubiquinol-cytochrome $c$ reductase complex $(7.2 \mathrm{kDa})$ & 29796 & 1.97 & 0.005 \\
\hline LDLR & LDL receptor & 3949 & 1.77 & 0.002 \\
\hline INSIG1 & Insulin-induced gene 1 & 3638 & $1 \cdot 76$ & 0.033 \\
\hline PDCD4 & $\begin{array}{l}\text { Programmed cell death } 4 \text { (neoplastic } \\
\text { transformation inhibitor) }\end{array}$ & 27250 & $1 \cdot 62$ & 0.006 \\
\hline UBE2T & Ubiquitin-conjugating enzyme E2T (putative) & 29089 & 1.61 & 0.047 \\
\hline SPINK4 & Serine peptidase inhibitor, Kazal type 4 & 27290 & 1.61 & 0.025 \\
\hline CABLES1 & Cdk5 and Abl enzyme substrate 1 & 91768 & 1.58 & 0.039 \\
\hline$B P I$ & Bactericidal/permeability-increasing protein & 671 & -1.51 & 0.047 \\
\hline SULT2A1 & $\begin{array}{l}\text { Sulfotransferase family, cytosolic, } 2 \mathrm{~A} \text {, } \\
\text { dehydroepiandrosterone-preferring, member } 1\end{array}$ & 6822 & -1.52 & 0.001 \\
\hline$P P I D$ & Peptidylprolyl isomerase D & 5481 & -1.53 & 0.023 \\
\hline SERPINF1 & $\begin{array}{l}\text { Serpin peptidase inhibitor, clade } F(\alpha-2 \text { antiplasmin, } \\
\text { pigment epithelium-derived factor), member } 1\end{array}$ & 5176 & -1.53 & 0.023 \\
\hline$F 13 B$ & Coagulation factor XIII, B polypeptide & 2165 & -1.55 & 0.007 \\
\hline CCND1 & Cyclin D1 & 595 & -1.59 & 0.047 \\
\hline PHF21B & PHD finger protein $21 \mathrm{~B}$ & 112885 & $-1 \cdot 60$ & 0.006 \\
\hline TCP1 & T-complex 1 & 6950 & -1.60 & 0.016 \\
\hline$H P X$ & Haemopexin & 3263 & $-1 \cdot 60$ & 0.015 \\
\hline SLC3A1 & Solute carrier family 3 member & 6519 & & \\
\hline ТTСЗ9А & Tetratricopeptide repeat domain $39 \mathrm{~A}$ & 22996 & -1.63 & 0.009 \\
\hline IFIT1 & $\begin{array}{l}\text { Interferon-induced protein with tetratricopeptide } \\
\text { r10170 repeats } 1\end{array}$ & 13434 & $-1 \cdot 72$ & 0.002 \\
\hline ANXA10 & Annexin A107350 & 11199 & -1.73 & 0.007 \\
\hline DHRS9 & Dehydrogenase/reductase (SDR family) member 9 & 10170 & $-1 \cdot 77$ & 0.002 \\
\hline UCP1 & Uncoupling protein 1 (mitochondrial, proton carrier) & 7350 & -1.83 & 0.009 \\
\hline GPX3 & Glutathione peroxidase 3 (plasma) & 2878 & -2.08 & 0.014 \\
\hline CRP (includes EG:1401) & C-reactive protein, pentraxin-related & 1401 & $-2 \cdot 31$ & 0.026 \\
\hline MT3 & Metallothionein 3 & 4504 & -2.57 & 0.005 \\
\hline UTS2D & Urotensin 2 domain containing & 257313 & $-2 \cdot 62$ & 0.037 \\
\hline$A V P$ & Arginine vasopressin & 551 & $-3 \cdot 29$ & 0.002 \\
\hline$R L N 1$ & Relaxin 1 & 6013 & -3.40 & 0.043 \\
\hline CTH & Cystathionase (cystathionine $\gamma$-lyase) & 1491 & -3.72 & 0.001 \\
\hline MT2A & Metallothionein $2 \mathrm{~A}$ & 4502 & $-3 \cdot 78$ & 0.003 \\
\hline MT1X & Metallothionein 1X & 4501 & $-4 \cdot 14$ & 0.039 \\
\hline
\end{tabular}

ID, identification; WD, tryptophan-aspartate; FYVE, domain identified in Fab1 $1_{p}$, YOTP, VAC1 $1_{p}$ and EEA1 domain; PHD, plant homeo domain.

bioactive molecules are still under investigation. The present experiment was conducted to investigate the dose-response effects of LC $n$-3 PUFA on liver lipid peroxidation and gene expression. For the first time, we demonstrated that increasing intake of LC $n$-3 PUFA enhances, in a dose-dependent manner, the hepatic production of 4-HHE, a specific peroxidised metabolite having cell signalling properties ${ }^{(24)}$. At the gene expression level, the different doses of LC $n-3$ PUFA tested induced contrasting effects on inflammation pathways and dose-dependently modulated the expression of major molecules involved in hepatic lipoprotein metabolism, possibly through a mechanism involving the FXR signalling pathway.

\section{Dietary LC n-3 PUFA modified lipid metabolic profiles}

The present results show for the first time that dietary LC $n-3$ PUFA increases, in a dose-dependent manner, not only the incorporation of LC $n-3$ PUFA in liver phospholipids but also the hepatic production of 4-HHE. As expected, the diets used here increased the content of DHA and, to a lesser extent, of EPA. The dose-dependent incorporation of DHA has previously been reported in various human tissues including liver ${ }^{(25)}$. This is usually associated with an equivalent decrease of arachidonic acid content because of their competition on the $s n-2$ position of phospholipids. This competition determines part of the biological effects of DHA since the relative proportion of arachidonic acid and DHA in phospholipids influences their availability for phospholipase cleavage and their subsequent metabolism into eicosanoids. These fatty acids and/or their metabolites are also involved in gene expression regulation. The present data did not show any significant change in arachidonic acid proportion despite the substantial increase of DHA in liver phospholipids, suggesting that the administrated doses were not sufficient to lower arachidonic acid levels. Indeed, in studies reporting a shift between arachidonic acid and DHA contents, the dose of LC $n$-3 PUFA (EPA or DHA) was higher than what is presently used: about $2 \%$ of daily energy intake ${ }^{(25,26)}$. Besides 
the effects of LC $n$-3 PUFA supplementation on the native fatty acids, we focused our attention on peroxidised metabolites, potential bioactive molecules involved in the modulation of gene expression. Interestingly, the dose-dependent production of 4-HHE was not associated with a decrease of 4-HNE. Overall, these modifications of lipid metabolic profiles suggest that the changes in gene expression levels are unlikely due to the reduced effects of arachidonic acid and/or 4-HNE, which were unchanged, but more probably due to DHA and/or 4-HHE, which were dose-dependently produced in response to LC $n$-3 PUFA supplementation.

Previous work showed increased level of lipoperoxidation in liver in response to fish oil feeding ${ }^{(27)}$ but to the best of our knowledge, none specifically identified 4-HHE and established a dose-response relationship. The signalling properties of hydroxyalkenals have been so far mainly focused on 4-HNE, the major aldehyde produced from $n-6$ fatty acid peroxidation. Studies have clearly indicated that concentrations of these aldehydes greatly influence their cellular effects, and that their signalling properties are mainly mediated through their capacity to form adducts with macromolecules, modifying their structure and function (recently reviewed in Poli et $a{ }^{(28)}$ ). Several kinases are targeted by 4-HNE, including c-Jun $\mathrm{NH}_{2}$-terminal kinase, p38 mitogen-activated protein kinases, IкB kinase (IKK) complex, extracellular signal-regulated kinase (ERK) and protein kinase $C \beta$ and $\gamma^{(29)}$, showing the involvement of 4 -HNE in the regulation of several pathophysiological processes including inflammation, proliferation, apoptosis and matrix remodelling. More recently, 4-HNE has been identified as an activator of PPAR $\gamma$ in 3T3-L1 preadipocytes $^{(30)}$, suggesting a different mechanism of gene expression modulation and the capacity of hydroxyalkenals to interact with transcription factors. Due to its low lipophilicity and reduced chemical reactivity, 4-HHE is considered less physiologically active than $4-\mathrm{HNE}^{(31)}$. However, previous studies $^{(32,33)}$ have demonstrated that 4-HHE modulates some kinase activities (p38 mitogen-activated protein kinases, ERK and IKK) leading to the activation of the NF- $\mathrm{BB}$ and the subsequent induction of the endothelial NO synthase expression. Altogether, these data suggest that the dose-dependent production of hepatic 4-HHE observed here might contribute to the alteration of gene expression in this tissue.

The doses of LC $n$-3 PUFA used in the present study did not affect plasma lipid profiles. However, even though hypocholesterolaemic and hypotriacylglycerolaemic effects of LC $n-3$ PUFA are well described in human subjects ${ }^{(34)}$, those are not always reported in animals ${ }^{(35)}$. It is possible that the highcholesterol-enriched diet (0.5\%) has induced a hypercholesterolaemia that was unable to be corrected by the doses of LC $n$-3 PUFA used. This is consistent with the study of Zhu et al. ${ }^{(36)}$, where, in a similar experimental design (rabbits fed a diet enriched with $0.3 \%$ cholesterol and three different doses of LC $n-3$ PUFA ranging from 0.9 to $2.7 \%$ of the daily energy intake), no effect was observed on total serum cholesterol and HDL-cholesterol. The hypotriacylglycerolaemic effect of LC $n-3$ PUFA was only detected with a dose of $1.8 \%$ of the daily energy intake, which is almost twice higher than the highest dose used in the present study.
In liver, LC $n$-3 PUFA and, more precisely, dose 3 substantially increased the TAG content. This unexpected effect was not dose-dependent and is not consistent with previous studies reporting that LC $n-3$ PUFA have no action on or do not prevent steatosis ${ }^{(37-39)}$. However, discrepancies of experimental designs (i.e. animal models, dose and type of LC $n$-3 PUFA used) make the comparison difficult. We can hypothesise that our original result could be linked to the specific effect of DHA and the high dose used, two parameters that deeply differ with the other studies. Even though the accumulation of liver TAG is surprising, this is consistent with the present transcriptomic results that are further discussed below.

\section{Dose-response effects of LC n-3 PUFA on pathways related to inflammation}

Among the top ten pathways of each group, those related to inflammation were systematically associated with datasets and the impact increased with the dose of LC $n$-3 PUFA. It is interesting to note that the first networks for each group were systematically centred on NFкB, a major transcription factor involved in inflammation ${ }^{(40)}$. This suggests that in our conditions, LC $n$-3 PUFA might have modified the expression of genes related to inflammation by modulating the activity of $\mathrm{NF} \mathrm{B}$ as reported previously ${ }^{(41)}$. However, differential effects were observed with the three doses. Group 2 was associated with an increased abundance of many genes encoding for pro-inflammatory cytokines and chemokines including IL-8, CXCL3 and CCL4 possibly through the activation of NFкB which controls the expression of all these genes ${ }^{(40)}$. In contrast, none of these genes was modified in group 3 but the expression levels of the pro-inflammatory protein C-reactive protein were substantially reduced, suggesting an anti-inflammatory effect with this dose of LC $n$-3 PUFA. As the expression of C-reactive protein is also under the control of $\mathrm{NF \kappa B}^{(42)}$, dose 3 might have then prevented the activation of NFкB. One might hypothesise that the discrepancies between groups 2 and 3 can be related to the production of $4-\mathrm{HHE}$ (twice more with dose 3 than with dose 2), which can be involved in the inactivation of NFкB. This would be consistent with studies showing that hydroxyalkenals can modulate NFкB activity; however, contrasting effects (i.e. activation or inhibition) have been reported $^{(24)}$. Indeed, it has been reported that 4-HNE prevents the activation of $\mathrm{NF \kappa B}$ by inhibiting the phosphorylation and subsequent degradation of the inhibitory proteins IкB $\alpha, \beta$ and $\varepsilon^{(43,44)}$. The inhibition appears to be caused by the formation of covalent adducts on the IKK complex ${ }^{(45)}$. In response to upstream stimuli, the IKK complex is activated through phosphorylation operated by IKK, namely protein kinase $\mathrm{C}$, protein kinase $\mathrm{B} / \mathrm{Akt}$ or mitogen-activated protein kinases/ERK 1,2 and $3^{(46)}$. On the other hand, others have reported in prostate endothelial cells that 4-HHE can activate NFкB by enhancing the phosphorylation of IкB via NFкB-inducing kinase and the p38 mitogen-activated protein kinases pathways ${ }^{(33)}$. These contrasting data together with the discrepancies between the groups observed here highlight that the effects of LC $n-3$ PUFA and/or their metabolites may be different and even 
opposite depending on the dose/intake and probably the cellular environment in which they operate.

\section{Dose-response effects of LC n-3 PUFA on lipid and lipoprotein metabolism}

As expected, several pathways and biological processes related to lipid metabolism were associated with datasets. Modulation of hepatic lipid metabolism by LC $n-3$ PUFA has been well described and generally involves an up-regulation of fatty acid transport, activation and oxidation (via up-regulation of fatty acid-binding proteins, acyl-CoA synthetases, acyl-CoA oxidase and carnitine palmitoyltransferase I) and a down-regulation of lipogenesis and desaturation of fatty acids (via down-regulation of fatty acid synthase and stearoyl-CoA desaturase 1$)^{(47)}$. Several transcription factors have been identified as prospective targets for fatty acid regulation of hepatic gene expression. These include a number of nuclear receptors such as the PPAR family $(\operatorname{PPAR} \alpha, \beta, \gamma 1$ and $\gamma 2$ ), retinoid $X$ receptor $\alpha$, liver $X$ receptor $\alpha$, FXR and hepatic nuclear factors $\alpha$ and $\gamma$, as well as several basic helix-loop-helix leucine-zipper transcription factors such as sterol regulatory element-binding protein- ${ }^{(48)}$. There are two main mechanisms that characterise fatty acid control of these transcription factors. In the first one, fatty acids bind directly to the transcription factors and control their activity, whereas in the second one, they control the nuclear abundance of key transcription factors such as sterol regulatory element-binding protein-1.

In the present experiment, LC $n$-3 PUFA (mainly DHA) significantly up-regulated acyl-CoA synthetases but most of the other genes involved in fatty acid transport, oxidation, elongation and lipogenesis were not altered. This suggests that PPAR $\alpha$, which controls the expression of almost all the genes involved in these processes ${ }^{(48)}$, was not activated. In a previous study using genome-wide analysis, EPA has been shown as reversing the decrease in colon expression levels of PPAR $\alpha$ in IL-10 gene-deficient mice (a model of inflammatory bowel disease), suggesting that EPA activated colon PPAR $\alpha$ to produce anti-inflammatory effects ${ }^{(49)}$. However, another microarray analysis of hepatic gene expression in response to LC $n$-3 PUFA, and predominantly DHA, failed to demonstrate a significant activation of the expression of genes controlled by PPAR $\alpha^{(50,51)}$. The absence of PPAR $\alpha$ activation in these studies (including the present study) can be explained by the fact that DHA and/or its metabolites (in contrast to EPA and/or its metabolites) are probably weak PPAR $\alpha$ ligands. Indeed, LC $n-3$ PUFA that include EPA, DHA and DPA are often considered as a whole while each fatty acid has specific physical and chemical properties influencing their biological activity. Concerning the ability of LC $n-3$ PUFA to activate PPAR $\alpha$, receptor-ligand assays have clearly demonstrated that DHA is one of the weakest PPAR $\alpha, \beta$ or $\gamma$ activators, whereas linoleic acid (a medium-chain $n$ - 6 fatty acid) is the strongest inducer of PPAR $\alpha$ and $\beta^{(52,53)}$. It is then consistent with the present data where the expression levels of PPAR $\alpha$-regulated genes were unchanged since DHA was the most abundant LC $n$-3 PUFA in liver phospholipids, whereas linoleic acid levels were lowered in a dose-dependent manner in response to DHA incorporation. PUFA's peroxidised metabolites are also recognised PPAR ligands ${ }^{(52,54,55)}$ but the only study which specifically investigated hydroxyalkenals showed that contrary to 4-HNE, 4-HHE was not able to induce PPAR $\beta / \gamma^{(30)}$. Thus, the use of a DHA-enriched diet here can explain the absence of the effect on PPAR $\alpha$-regulated genes. In contrast, our datasets were clearly associated with the FXR signalling pathway, which suggests that DHA preferentially binds with this nuclear receptor, consistent with recent findings showing that it is a ligand for $\mathrm{FXR}^{(56)}$ and that DHArich oil consumption was correlated with FXR activation in rat liver $^{(51)}$.

Despite the absence of modulation of the usual lipid metabolism pathways, major genes encoding proteins involved in TAG-rich lipoprotein metabolism were altered by LC $n-3$ PUFA. These include the receptors for LDL and VLDL (LDLR and VLDL-receptor (VLDLR)), whose mRNA abundances were increased, as well as the MTTP, whose expression level decreased with doses 1 and 2 . These modulations are consistent with a previous study investigating transcription profiling in rat liver in response to $\mathrm{DHA}^{(51)}$. The increased expression of LDLR and VLDLR was mostly associated with the highest dose of LC $n$-3 PUFA and could explain the hepatic accumulation of TAG reported in group 3. Indeed, LDLR and VLDLR are both involved in the clearance of TAG-rich lipoproteins ${ }^{(57)}$ and therefore enhance the hepatic uptake of circulating lipids This effect could be interesting to reduced plasma TAG concentration provided that it is associated with a stimulation of fatty acid oxidation and/or an inhibition of lipogenesis. However, this was not the case in the present experiment, which might have contributed to the accumulation of TAG in liver. With doses 1 and 2, the mRNA abundances of VLDLR and LDLR were slightly or not modified but MTTP was down-regulated. This protein is essential for hepatic VLDL secretion because of its involvement in the translocation and maturation of apoB molecules as well as its role in the transfer of TAG upon binding to $\operatorname{apoB}^{(58)}$. The reduction of the mRNA levels of MTTP might then lead to a reduced VLDL secretion. This is a well-known effect of LC $n-3$ PUFA but usually attributed to reduced expression levels of genes encoding for fatty acid synthesis together with an increased mRNA abundance of genes involved in fatty acid oxidation and induced by a PPAR $\alpha$-dependent pathway ${ }^{(2)}$. In the present experiment, and consistent with the results reported by Kramer et al. ${ }^{(51)}$ in rats, PPAR $\alpha$ genes were not regulated, whereas the FXR signalling pathway was induced. Interestingly, LDLR and VLDLR are all induced by FXR ${ }^{(59,60)}$ and MTTP is indirectly repressed when FXR is activated via the inhibition of hepatic nuclear factor 1 (data from IPA). Therefore, we can hypothesise that in the present experiment, DHA (the most abundant LC $n-3$ PUFA in diets and in liver phospholipids) and/or its metabolites activated FXR that induced the expression of LDLR and VLDLR and the repression of MTTP expression.

In conclusion, the present study shows that feeding LC $n$-3 PUFA to hypercholesterolaemic rabbits induced, in a dose-dependent manner, the deposition of these fatty acids (especially DHA) in liver phospholipids but also the 
production of 4-HHE, a major aldehyde produced from LC $n$-3 PUFA peroxidation. At the highest dose, LC $n$-3 PUFA provoked an increased deposition of TAG in liver, which can be directly linked to the increased mRNA levels of lipoprotein hepatic receptors (LDLR and VLDLR). Interestingly, LC $n-3$ PUFA supplementation induced a dose-dependent activation of pathways related to inflammation, with contrasting effects depending on the dose used. Although the discrimination of the effects attributable to the native DHA or 4-HHE is impossible here, the literature provides evidence suggesting that some of the observed changes in gene expression levels might be induced by 4-HHE. Complementary studies using in vitro models (e.g. hepatic cell lines) and purified molecules are now required for further understanding of the mechanisms of the action of DHA and/or its metabolites on liver gene expression.

\section{Acknowledgements}

The authors acknowledge Marie-Anne Verny, Benoit Cohade and Christian Lafarge for their excellent assistance during the animal experiment. We also thank Chrystèle Jouve and Dominique Bayle for the analysis of lipid parameters in plasma and liver. The authors finally wish to thank Anna Russ and Dragan Milenkovic for their advices on the use of bioinformatic software. Finally thanks to Kelly Armstrong and Michelle for their assistance with tissue RNA extraction and array hybridisation. The present study received no specific grant from any funding agency in the public, commercial or not-for-profit sectors. C. G., N. C. R., J.-M. C. and B. C. planned the study, designed the experiment, summarised, discussed and interpreted the results or drafted the manuscript. Other authors were involved in the analysis of biological samples and interpretation of the results as well as participated in the writing of the manuscript. The authors have no potential financial or personal conflict of interest.

\section{References}

1. Kim W, McMurray DN \& Chapkin RS (2010) n-3 Polyunsaturated fatty acids-physiological relevance of dose. Prostaglandins Leukot Essent Fatty Acids 82, 155-158.

2. Harris WS, Miller M, Tighe AP, et al. (2008) Omega-3 fatty acids and coronary heart disease risk: clinical and mechanistic perspectives. Atherosclerosis 197, 12-24.

3. Davidson MH (2006) Mechanisms for the hypotriglyceridemic effect of marine omega-3 fatty acids. Am J Cardiol 98, $27 \mathrm{i}-33 \mathrm{i}$.

4. Jump DB (2002) Dietary polyunsaturated fatty acid regulation of hepatic gene transcription. Scand J Nutr/Naringsforskning 46, 59-67.

5. Cosgrove JP, Church DF \& Pryor WA (1987) The kinetics of the autoxidation of polyunsaturated fatty-acids. Lipids $\mathbf{2 2}$, 299-304.

6. Vankuijk F, Holte LL \& Dratz EA (1990) 4-Hydroxyhexenal a lipid-peroxidation product derived from oxidized docosahexaenoic acid. Biochim Biophys Acta 1043, 116-118.

7. Leonarduzzi G, Arkan MC, Basaga H, et al. (2000) Lipid oxidation products in cell signaling. Free Radic Biol Med 28 , $1370-1378$.
8. Yanni AE (2004) The laboratory rabbit: an animal model of atherosclerosis research. Lab Anim 38, 246-256.

9. Kris-Etherton PM, Grieger JA \& Etherton TD (2009) Dietary reference intakes for DHA and EPA. Prostaglandins Leukot Essent Fatty Acids 81, 99-104.

10. Folch J, Lees M \& Sloane Stanley GH (1957) A simple method for the isolation and purification of total lipides from animal tissues. J Biol Chem 226, 497-509.

11. Juaneda P \& Rocquelin G (1985) Rapid and convenient separation of phospholipids and non phosphorus lipids from rat-heart using silica cartridges. Lipids 20, 40-41.

12. Ledoux M, Chardigny JM, Darbois M, et al. (2005) Fatty acid composition of French butters, with special emphasis on conjugated linoleic acid (CLA) isomers. J Food Compos Anal 18, 409-425.

13. Griffith OW (1980) Determination of glutathione and glutathione disulfide using glutathione-reductase and 2-vinylpyridine. Anal Biochem 106, 207-212.

14. Flohe L \& Gunzler WA (1984) Assays of glutathione-peroxidase. Methods Enzymol 105, 114-121.

15. Carlberg I \& Mannervik B (1985) Glutathione-reductase. Methods Enzymol 113, 484-490.

16. Habig WH, Pabst MJ \& Jakoby WB (1974) Glutathione $S$-transferases - first enzymatic step in mercapturic acid formation. J Biol Chem 249, 7130-7139.

17. Sunderman FW, Marzouk A, Hopfer SM, et al. (1985) Increased lipid-peroxidation in tissues of nickel chloridetreated rats. Ann Clin Lab Sci 15, 229-236.

18. Asselin C, Bouchard B, Tardif JC, et al. (2006) Circulating 4-hydroxynonenal-protein thioether adducts assessed by gas chromatography-mass spectrometry are increased with disease progression and aging in spontaneously hypertensive rats. Free Radic Biol Med 41, 97-105.

19. Smyth GK, Michaud J \& Scott HS (2005) Use of withinarray replicate spots for assessing differential expression in microarray experiments. Bioinformatics 21, 2067-2075.

20. Smyth GK \& Speed T (2003) Normalization of cDNA microarray data. Methods 31, 265-273.

21. Sulzle A, Hirche F \& Eder K (2004) Thermally oxidized dietary fat upregulates the expression of target genes of PPARa in rat liver. J Nutr 134, 1375-1383.

22. Taniguchi M, Miura K, Iwao H, et al. (2001) Quantitative assessment of DNA microarrays - comparison with Northern blot analyses. Genomics 71, 34-39.

23. Hosack DA, Dennis G, Sherman BT, et al. (2003) Identifying biological themes within lists of genes with EASE. Genome Biol 4, R70.

24. Riahi Y, Cohen G, Shamni O, et al. (2010) Signaling and cytotoxic functions of 4-hydroxyalkenals. Am J Physiol Endocrinol Metab 299, E879-E886.

25. Arterburn LM, Hall EB \& Oken H (2006) Distribution, interconversion, and dose response of $n-3$ fatty acids in humans. Am J Clin Nutr 83, 1467S-1476S.

26. Berger A \& German JB (1990) Phospholipid fatty-acid composition of various mouse-tissues after feeding alphalinolenate $(18: 3 n-3)$ or eicosatrienoate (20:3n-3). Lipids 25, 473-480.

27. Sen CK, Atalay M, Agren J, et al. (1997) Fish oil and vitamin E supplementation in oxidative stress at rest and after physical exercise. J Appl Physiol 83, 189-195.

28. Poli G, Schaur RJ, Siems WG, et al. (2008) 4-Hydroxynonenal: a membrane lipid oxidation product of medicinal interest. Med Res Rev 28, 569-631.

29. Leonarduzzi G, Robbesyn F \& Poli G (2004) Signaling kinases modulated by 4-hydroxynonenal. Free Radic Biol Med 37, 1694-1702. 
30. Coleman JD, Prabhu KS, Thompson JT, et al. (2007) The oxidative stress mediator 4-hydroxynonenal is an intracellular agonist of the nuclear receptor peroxisome proliferator-activated receptor-beta/delta (PPAR beta/delta). Free Radic Biol Med 42, 1155-1164.

31. Esterbauer H, Schaur RJ \& Zollner H (1991) Chemistry and biochemistry of 4-hydroxynonenal, malonaldehyde and related aldehydes. Free Radic Biol Med 11, 81-128.

32. Lee JY, Je JH, Jung KJ, et al. (2004) Induction of endothelial iNOS by 4-hydroxyhexenal through NF-kappa b activation. Free Radic Biol Med 37, 539-548.

33. Je JH, Lee JY, Jung KJ, et al. (2004) NF-kappa B activation mechanism of 4-hydroxyhexenal via NIK/IKK and p38 MAPK pathway. FEBS Lett 566, 183-189.

34. Harris WS (1997) n-3 Fatty acids and serum lipoproteins: human studies. Am J Clin Nutr 65, (Suppl. 5), 1645S-1654S.

35. Harris WS (1997) $n-3$ Fatty acids and serum lipoproteins: animal studies. Am J Clin Nutr 65, (Suppl. 5), 1611S-1616S.

36. Zhu BQ, Smith DL, Sievers RE, et al. (1988) Inhibition of atherosclerosis by fish oil in cholesterol-fed rabbits. $\mathrm{J} \mathrm{Am}$ Coll Cardiol 12, 1073-1078.

37. Saraswathi V, Gao L, Morrow JD, et al. (2007) Fish oil increases cholesterol storage in white adipose tissue with concomitant decreases in inflammation, hepatic steatosis, and atherosclerosis in mice. J Nutr 137, 1776-1782.

38. Larter CZ, Yeh MM, Cheng J, et al. (2008) Activation of peroxisome proliferator-activated receptor alpha by dietary fish oil attenuates steatosis, but does not prevent experimental steatohepatitis because of hepatic lipoperoxide accumulation. J Gastroenterol Hepatol 23, 267-275.

39. Tandy S, Chung RWS, Wat E, et al. (2009) Dietary krill oil supplementation reduces hepatic steatosis, glycemia, and hypercholesterolemia in high-fat-fed mice. J Agric Food Chem 57, 9339-9345.

40. Hayden MS \& Ghosh S (2004) Signaling to NF-kappa B. Genes Dev 18, 2195-2224.

41. Calder PC (2006) n-3 Polyunsaturated fatty acids, inflammation, and inflammatory diseases. Am J Clin Nutr 83, 1505S-1519S.

42. Agrawal A, Cha-Molstad H, Samols D, et al. (2003) Overexpressed nuclear factor-kappa $\mathrm{B}$ can participate in endogenous C-reactive protein induction, and enhances the effects of C/EBP beta and signal transducer and activator of transcription-3. Immunology 108, 539-547.

43. Page S, Fischer C, Baumgartner B, et al. (1999) 4-Hydroxynonenal prevents NF-kappa B activation and tumor necrosis factor expression by inhibiting I kappa B phosphorylation and subsequent proteolysis. J Biol Chem 274, 11611-11618.

44. Donath B, Fischer C, Page S, et al. (2002) Chlamydia pneumoniae activates IKK/I kappa B-mediated signaling, which is inhibited by 4-HNE and following primary exposure. Atherosclerosis 165, 79-88.

45. Ji C, Kozak KR \& Marnett LJ (2001) I kappa B kinase, a molecular target for inhibition by 4-hydroxy-2-nonenal. $J$ Biol Chem 276, 18223-18228.
46. Zandi E \& Karin M (1999) Bridging the gap: composition, regulation, and physiological function of the I kappa B kinase complex. Mol Cell Biol 19, 4547-4551.

47. Pegorier JP, May Cl \& Girard J. (2004) Control of gene expression by fatty acids. J Nutr 134, 2444S-2449S.

48. Jump DB, Botolin D, Wang Y, et al. (2008) Docosahexaenoic acid (DHA) and hepatic gene transcription. Chem Phys Lipids 153, 3-13.

49. Knoch B, Barnett MPG, Zhu S, et al. (2009) Genome-wide analysis of dietary eicosapentaenoic acid- and oleic acidinduced modulation of colon inflammation in interleukin10 gene-deficient mice. I Nutrigenet Nutrigenomics 2, 9-28.

50. Takahashi M, Tsuboyama-Kasaoka N, Nakatani $\mathrm{T}$, et al. (2002) Fish oil feeding alters liver gene expressions to defend against PPAR alpha activation and ROS production Am J Physiol-Gastrointest Liver Physiol 282, G338-G348.

51. Kramer JA, LeDeaux J, Butteiger D, et al. (2003) Transcription profiling in rat liver in response to dietary docosahexaenoic acid implicates stearoyl-coenzyme A desaturase as a nutritional target for lipid lowering. J Nutr 133, 57-66.

52. Krey G, Braissant O, Lhorset F, et al. (1997) Fatty acids, eicosanoids, and hypolipidemic agents identified as ligands of peroxisome proliferator-activated receptors by coactivatordependent receptor ligand assay. Mol Endocrinol 11, 779-791.

53. Pawar A \& Jump DB (2003) Unsaturated fatty acid regulation of peroxisome proliferator-activated receptor alpha activity in rat primary hepatoctes. J Biol Chem 278, 35931-35939.

54. Mishra A, Chaudhary A \& Sethi S (2004) Oxidized omega-3 fatty acids inhibit NF-kappa B activation via a PPAR alphadependent pathway. Arterioscler Thromb Vasc Biol 24, 1621-1627.

55. Itoh $\mathrm{T} \&$ Yamamoto $\mathrm{K}$ (2008) Peroxisome proliferator activated receptor gamma and oxidized docosahexaenoic acids as new class of ligand. Naunyn Schmiedebergs Arch Pharmacol 377, 541-547.

56. Zhao A, Yu JH, Lew JL, et al. (2004) Polyunsaturated fatty acids are FXR ligands and differentially regulate expression of FXR targets. DNA Cell Biol 23, 519-526.

57. Daniels TF, Killinger KM, Michal JJ, et al. (2009) Lipoproteins, cholesterol homeostasis and cardiac health. Int J Biol Sci 5, 474-488.

58. Fisher EA \& Ginsberg HN (2002) Complexity in the secretory pathway: the assembly and secretion of apoB-containing lipoproteins. J Biol Chem 277, 17377-17380.

59. Sirvent A, Claudel T, Martin G, et al. (2004) The farnesoid X receptor induces very low density lipoprotein receptor gene expression. FEBS Lett 566, 173-177.

60. Claudel T, Staels B \& Kuipers F (2005) The farnesoid X receptor - a molecular link between bile acid and lipid and glucose metabolism. Arterioscler Thromb Vasc Biol 25, 2020-2031. 